OPEN ACCESS

Edited by:

Teng Wu,

University at Buffalo, United States

Reviewed by:

Franklin Lombardo,

University of Illinois at

Urbana-Champaign, United States

Solomon Tesfamariam,

University of British Columbia, Canada

Guoqing Huang,

Chongqing University, China

${ }^{*}$ Correspondence:

Giovanni Solari

giovanni.solari@unige.it

TORCID:

Giovanni Solari

orcid.org/0000-0002-2376-4498

Specialty section:

This article was submitted to Wind Engineering and Science,

a section of the journal

Frontiers in Built Environment

Received: 11 December 2019

Accepted: 15 April 2020

Published: 22 May 2020

Citation:

Solari G (2020) Thunderstorm Downbursts and Wind Loading of Structures: Progress and Prospect.

Front. Built Environ. 6:63.

doi: 10.3389/fbuil.2020.00063

\section{Thunderstorm Downbursts and Wind Loading of Structures: Progress and Prospect}

\author{
Giovanni Solari ${ }^{*+}$ \\ Department of Civil, Chemical and Environmental Engineering, Polytechnic School, University of Genova, Genova, Italy
}

In 1961, Davenport published a paper, considered by most to be a critical work in the study of wind engineering, in which meteorology, micrometeorology, climatology, aerodynamics, and structural dynamics were embedded in a homogeneous framework of the wind loading of structures. This framework, known as Davenport chain and based on a wind model coherent with synoptic-scale extra-tropical cyclones, is so limpid as to become a sort of axiom. In 1977, Gomes and Vickery separated thunderstorm from non-thunderstorm winds, evaluated their extreme wind speed marginal distributions, and from them obtained a mixed statistical model later generalized to other wind types. This viewpoint, dealt with as a milestone in the emerging issue of mixed climatology, pointed out the difficulty of labeling a heterogeneous set of phenomena endowed with different velocity fields, frequencies, durations, and sizes by the generic term "wind." Many wind types, in particular tropical cyclones, tornadoes, and downslope winds are typical of limited and well-known areas. Extra-tropical depressions and thunderstorms are natural hazards that affect the whole planet. This paper provides a state-of-the-art discussion of thunderstorm downburst, one of the most spectacular and damaging events caused by nature, and its wind loading of structures. Also, in light of the planet's climatology evolution, this topic is a key issue of structural safety and sustainability.

Keywords: downburst, extra-tropical cyclone, mixed climatology, synoptic wind, thunderstorm, wind loading of structures

\section{INTRODUCTION}

Cermak (1975) defined wind engineering as "the rational treatment of the interactions between wind in the atmospheric boundary layer and man and his works on the surface of Earth." The International Association for Wind Engineering (IAWE) "promotes international co-operation among scientists, engineers, and other professionals for the advancement of knowledge in the broad field of wind engineering" (Solari, 2007).

The transformation of a heterogeneous set of arguments associated with wind in a homogeneous and autonomous matter derived from a series of studies on wind actions and effects on structures carried out between the end of the nineteenth century and the mid of the twentieth century (Solari, 2019b). Fidler (1887) issued a state-of-the-art perspective on wind loading on bridges, whose content transcended this structural type, anticipating the themes most debated by modern wind engineering. Eiffel (1909) collected, together with the results of his own research, a synthesis of what was known about the wind at his time; he noted how the problem of wind strength, essential in aeronautics, had also become very important in civil engineering. Fleming (1930) dealt with 
the wind loading of buildings transcending this specific structural type and providing a picture of the wind knowledge. Pagon (1934-1935) pursued the transfer of knowledge in meteorology and aerodynamics to civil engineering. Karman (1948) shared applications and prospects of aerodynamics in engineering and industrial disciplines. American Society of Civil Engineers (1961) offered a state-of-the-art look at wind forces on structures. Davenport (1961) published a paper, considered a critical work in the field of wind engineering, in which meteorology, micrometeorology, climatology, aerodynamics, and structural dynamics were embedded in a homogeneous framework of the wind loading of structures. This framework, the "Davenport chain," opened new perspectives to the design of windsensitive structures, generating a growing interest in structural engineering toward this subject.

At the same time in a partially provocative way, the Davenport chain represented a sort of straitjacket in which wind engineering was trapped. In this framework, referred to as an extra-tropical cyclone at synoptic scale, the mean wind velocity, assumed intense, has a vertical profile in equilibrium with a neutrally stratified atmospheric boundary layer with a depth in the order of $1-3 \mathrm{~km}$; in addition, within time intervals between $10 \mathrm{~min}$ and $1 \mathrm{~h}$ (Van der Hoven, 1957), the turbulent field is dealt with as stationary and Gaussian. This model is so clear and elegant as to have become a sort of axiom for wind engineering.

In reality, a few years later, Davenport (1968) himself published another paper including a prophetic view point. Extracting from it the most relevant remarks, he wrote: "In formulating wind statistics the question has been posed as to whether intense local storms including tornadoes and thunderstorms conform to the wind structure of large scale storms. Tornado probability is an order of magnitude different from other storm winds. A design approach based on fail-safe concepts is indicated. The question of thunderstorms is less clear cut. In certain parts of the world it appears that a significant proportion of maximum gusts arise from thunderstorms. Wittingham (1964) in his analysis of the Australian wind conditions shows that as much as $50 \%$ of maximum winds occur in thunderstorms. These storms may last 5-10 min and subside rapidly during which time severe convective turbulence may induce strong gusts. From the design point of view, the question is probably best treated by adopting an approach in which the mean velocities are obtained for intervals short enough to reflect the higher winds prevalent in the thunderstorm and assume turbulence response characteristic of other major storms. Eventually, it may be possible to treat thunderstorms separately ..."

These concepts were first taken up by Gomes and Vickery (1976, 1977/1978), who developed a study of the extreme wind velocity in Australia, where thunderstorms were separated from non-thunderstorm winds, marginal extreme distributions were determined, and a mixed statistical model later generalized to other types was derived. Their second paper represents a milestone for the emerging issue of mixed climatology. Far beyond the principle of separating different phenomena to evaluate their extreme wind speed, it pointed out the difficulty of labeling a heterogeneous set of wind types endowed with different velocity fields, frequencies, durations, and sizes with the generic word "wind." Many of these-tropical cyclones, tornadoes, monsoons, and down-slope winds-usually happen in limited well-known areas. Extra-tropical depressions and downbursts caused by thunderstorms are natural hazards that affect the whole planet. Also, in light of the planet's climatology evolution, there is today a widespread conviction that design wind speeds with return periods above 10-20 years are often due to thunderstorm downbursts (Letchford et al., 2002; Solari, 2014). This topic thus represents a key issue for structural safety and sustainability.

After these introductory notes, this paper offers a brief description of thunderstorms and downbursts, one of the most spectacular and damaging events produced by nature and by thunderstorms (section Thunderstorms and Downbursts). It then develops a state-of-the-art review of the studies in this field with regard to wind detection and measurement (section Wind Detection and Measurement), statistics and climatology (section Wind Speed Statistics and Climatology), modeling and simulation (section Wind Modeling and Simulation), structural loading (section Wind Loading of Structures), and response (section Wind-Excited Response of Structures). Finally, having excluded such contributions from previous sections, it describes the research carried out on this topic at the University of Genova (section Research on Thunderstorms at the University of Genova). The conclusions and prospects are given in section Conclusions and Prospects. In its entirety, this paper provides a substantial extension and generalization of the contents of a lecture delivered by the author at the 15th International Conference of the Italian Association for Wind Engineering (Solari, 2019a).

\section{THUNDERSTORMS AND DOWNBURSTS}

Since ancient times, thunderstorms have attracted the interest first of philosophers, then of scientists, and finally of engineers (Solari, 2019b). Among many others, they were studied by Anassimandro of Mileto in the sixth century B.C., Titus Lucretius Carus (60 B.C.), Lucius Anneus Seneca (41 A.D.), Bohun (1671), Espy (1841), Peltier (1841), Finley (1882), Möller (1884), Ferrel (1889), Davis (1894), Brooks (1922), Simpson and Scrase (1937), and Suckstorff (1938).

The turning point in the knowledge of thunderstorm cells took place mostly thanks to Horace Byers, appointed to head Thunderstorm Project, the joint research carried out in the U.S. between 1946 and 1947. This project focused on nine elements: (1) updrafts and downdrafts, (2) inward and outward horizontal motions, (3) horizontal and vertical temperature gradients, (4) electric fields, (5) rain distribution and intensity, (6) temperature change at ground level, (7) pressure change at ground level, (8) fluctuations in the surface wind speed, and (9) turbulence and wind gusts. Measurements were carried out by instrumented airplanes, balloons released from several stations and tracked by radar, and a network of 55 stations, each one equipped with 

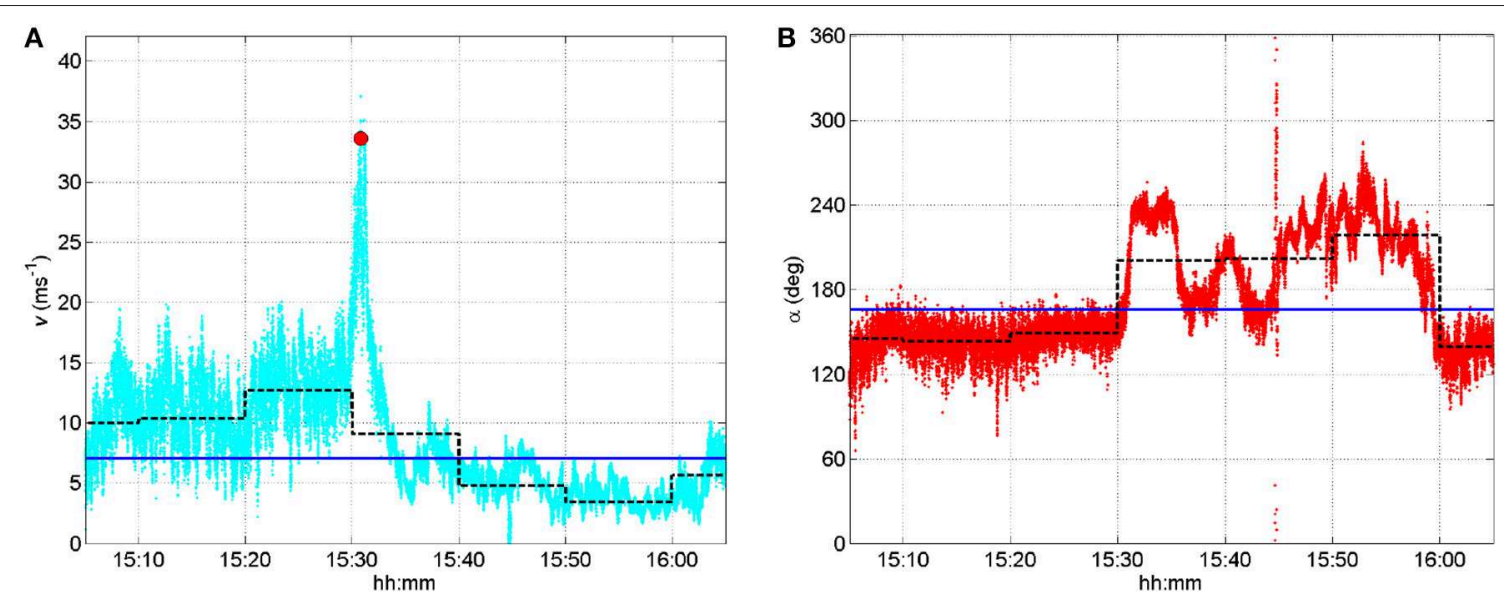

FIGURE 1 | Wind speed (A) and direction (B) recorded on 25 October 2011 in the Port of La Spezia. Reproduced from De Gaetano et al. (2014) with permission from Elsevier.

pluviometers, hygrothermographs, barographs, anemometers, and wind vanes. Radars unified the collected data and positioned the airplanes.

Measurements showed that a thunderstorm is an intense form of convection (Byers and Braham, 1949). It gives rise to a wild cloud, accompanied by lightning and thunder, gusty winds, heavy rain, and sometimes hail. It consists of cells organized randomly or in squall-lines. In each cell, an event lasting $\sim 30 \mathrm{~min}$ and evolving through three stages takes place: (1) cumulus stage, due to unstable phenomena of a convective nature, in which an updraft of hot air causes a cumulus; (2) mature stage, in which intense precipitation occurs together with a downdraft of cold air that spreads at ground level, causing sudden wind changes, temperature drops, and pressure growth; (3) dissipative stage, in which the thunderstorm loses strength and disappears.

A turning point happened in the 1950s and 1960s, when Doppler radar begun to be used for meteorological aims (Barratt and Browne, 1953; Smith and Holmes, 1961) and, in particular, to detect thunderstorms and tornadoes (Brown and Lewis, 2005). Also thanks to these technological advances, in the 1970 s and 1980s Fujita (1981, 1985, 1990), Fujita and Wakimoto (1981), and Wilson and Wakimoto (2001) gave new fundamental contributions (section Causes, Morphology, and Life-Cycle of Thunderstorms), showing that the downdraft that impacts Earth's surface produces radial outflows and ring vortices. Fujita (1985) called the ensemble of these air flows "downbursts" and divided them into "macro-bursts" and "micro-bursts" depending on whether their size was greater or smaller than $4 \mathrm{~km}$. Under this viewpoint, downbursts are one of the most spectacular and dangerous events due to thunderstorms.

These discoveries were supported by three projectsNIMROD (Northern Illinois Meteorological Research on Downbursts, 1978), JAWS (Joint Airport Weather Studies, 1982), and MIST (Microburst and Severe Thunderstorms, 1986) - which provided a huge amount of measurements. In particular, they showed that radial outflows are characterized by transient fields (Figure 1) with a nose profile that increases up to 50-100 m height, then decreases (Goff, 1976). In addition, they gave rise to extensive research in atmospheric science,

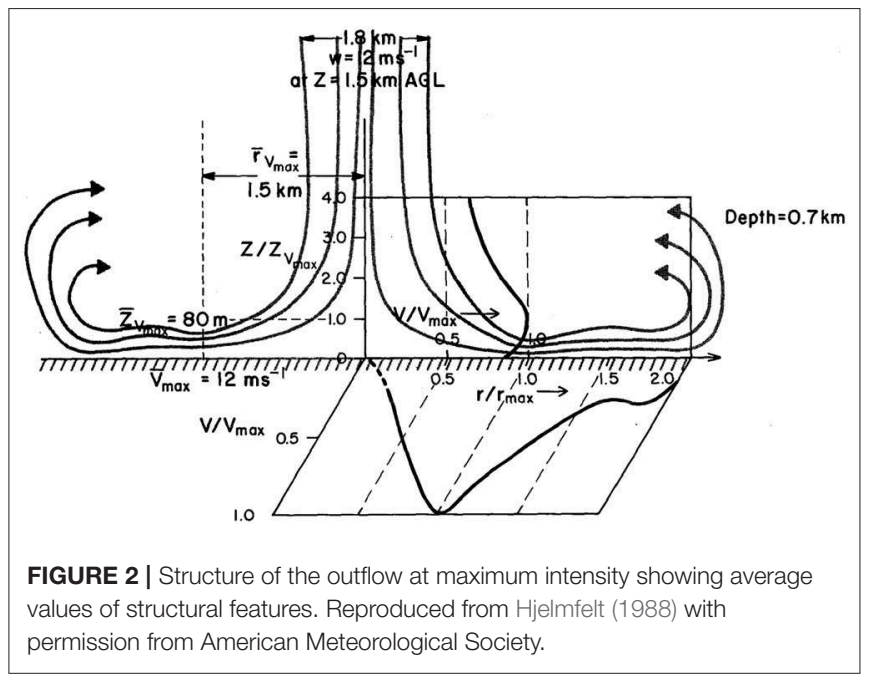

focusing on the causes, morphology (Figure 2), and life cycle of thunderstorms (Hjelmfelt, 1988).

Meanwhile, wind engineering recognized that design wind speed and severe wind damage (Figure 3) were often due to thunderstorm outflows (Letchford et al., 2002). Hence, a striking research occurred in this field, parallel to that which was developed in atmospheric science (Solari, 2014).

Despite this situation, however, this topic is still characterized by many uncertainties and the lack of a shared model for thunderstorm outflows and their loading of structures, like that introduced by Davenport (1961) for synoptic winds (Letchford and Lombardo, 2015). This is mainly due to the complexity of downbursts that makes it difficult to formulate physically realistic and simple models. Their short duration and small extension are responsible for a limited amount of measurements. The persisting gap between wind engineering and atmospheric science does not contribute to improving the situation. It follows that the wind loading of structures is still determined by Davenport's model at the most considering downbursts, if data are available, in the statistical evaluation of the wind 

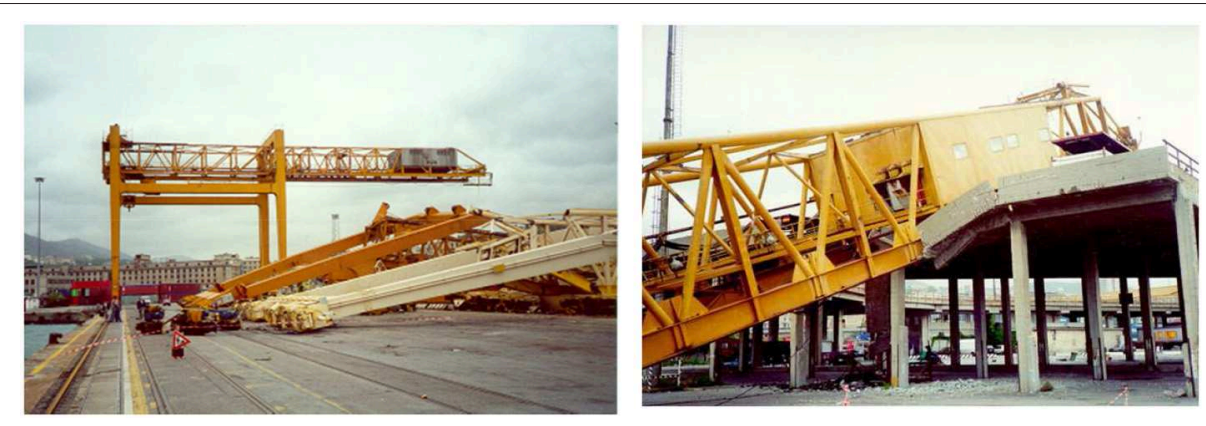

FIGURE 3 | Damage caused by a downburst in the seaport of Genova (August 31, 1994).

speed (Gomes and Vickery, 1977/1978). This cannot be enough since synoptic winds and thunderstorm outflows are different phenomena that need different evaluations (Solari, 2014).

\section{WIND DETECTION AND MEASUREMENT}

The evolution of the detection and measurement systems gave rise to impressive progress along two complementary lines. On the one hand, meteorological research has been developed that studied the section Causes, Morphology, and Life Cycle of Thunderstorms. On the other hand, wind engineering produced wind measurements and signal analyses aiming to gather elements relevant for evaluating the thunderstorm loading of structures (section Wind Speed Recording). The line of demarcation between these trends, sometimes blurred but often clearly marked, is an apparent obstacle toward a general and global view of this phenomenon. Section Damage Survey provides an overview of the first damage surveys, a topic that is receiving increasing interest in atmospheric science and wind engineering.

\section{Causes, Morphology, and Life-Cycle of Thunderstorms}

The modern study of the causes, morphology, and life cycle of thunderstorms lays its foundations in a series of contributions appearing between 1970 and 1990 .

Goff (1976) illustrated the detection of 20 thunderstorm outflows carried out between 1971 and 1973 on a $461 \mathrm{~m}$ high Oklahoma tower; it was equipped with sensors for measuring horizontal and vertical speed, temperature, pressure, humidity and precipitation. Taking advantage of radar measurements, he showed that each outflow depends on the properties of the thunderstorm that generates it and on the thermal characteristics of both the colder outflow and the warmer ambient air. Meanwhile, he studied the profile of the gust fronts and classified the thunderstorm outflows into four types according to the corresponding thunderstorm stage: accelerating outflows were associated to intensifying storms, quasi-steady outflows to mature intense storms, decelerating outflows to dissipating storms, and gust fronts refer to the final stage of the thunderstorm life-cycle. Goff also studied the outflow kinematics in great detail, and was the first scholar to describe the nose-like shape of the outflow vertical velocity profiles as well as the updraft of the warmer air displaced in advance of the gust front that often comes before the vortex ring. According to their horizontal size, he also identified five scales, called maso- (A), meso- (E), miso- (I), moso- $(\mathrm{O})$, and muso- $(\mathrm{U})$. The maso-scale corresponds to the equator length and is the maximum. Each subsequent scale has a size smaller than a factor 100 . The extreme wind speeds caused by thunderstorms are related to flows with miso- and moso-scales induced by a generating phenomenon with a meso-scale.

Lilly (1979) described the properties of severe thunderstorms, including the theory behind the idealized isolated storm model, with and without shear, as well as the squall line model, in which thunderstorms are organised along cold fronts or dry lines.

The concept of time scale was taken up by Fujita and Wakimoto (1981), who evaluated the wind speed based on debris caused by thunderstorms. Hence, a classification of thunderstorms according to five scales was derived: (1) the masoBETA scale corresponds to a family of downburst clusters, (2) the meso-ALFA scale corresponds to a downburst cluster, (3) the meso-BETA scale corresponds to a downburst, (4) the misoALFA scale corresponds to a microburst with a life no more than 20-min, and (5) the miso-BETA scale corresponds to a burst swath inside a downburst or a microburst.

Wakimoto (1982) described the life cycle of the thunderstorms gust front detected by Doppler radar and radio-sounding. Differently from Byers and Braham's scale (1949), they identify four stages of the gust fron evolution called: (1) formative, (2) mature, (3) late mature, and (4) dissipating. The formative stage occurs during the mature stage of a thunderstorm cloud development Byers and Braham (1949), immediately after the downdraft touchdown has occurred, when the vortex ring is not well developed yet and spreading outward has just started. The last three stages of the gust fronts, namely mature, late and dissipating, occur during the dissipating stage of the thunderstorm cloud, when the vortex ring starts propagating outwards until it gets so far from the touchdown that it dissipates because of turbulence and mixing with the surrounding warmer ambient air.

Wilson et al. (1984) used Doppler radar data to determine the horizontal and vertical structure of the wind field caused by microbursts. Usually, the downdraft was about $1 \mathrm{~km}$ wide and began to spread horizontally below $1 \mathrm{~km}$ height. The average time from the initial divergence at the surface to the maximum wind speed instant was 5 -min. The height of the maximum velocity was nearly $75 \mathrm{~m}$. The outflow was non-symmetric. Besides examining the most relevant microburst characteristics, 
the authors proposed three Doppler systems for providing wind shear detection to terminal areas by dual- or single-Doppler radar systems deployed in the airport area or in off-airport positions.

Hjelmfelt (1988) inspected the structure and life cycle of microburst outflows of 27 microburst events detected in Colorado. The wind fields were obtained by three Doppler radars, surface speed measures, and radio-sounding. The microbursts were separated into wet and dry, as well as into individual and lines. The spatial-temporal evolution of these events was illustrated by the variation of the velocity over time, the profiles of the radial velocity at the maximum speed, and the vertical profile normalized to the maximum velocity height (Figure 2), showing in particular that at a distance from the touchdown of 1.5-2.0 times the downdraft radius, the microburst outflow profiles and the wall jet profiles are very similar. Hjelmfelt also analysed the outflow symmetry of the advancing vortex ring, showing that it cannot be symmetric in terms of intensity.

Fujita $(1985,1990)$ provided a link between meteorological aspects and wind field properties. The diagram of the wind speed recorded by a propeller anemometer close to the ground at the Andrews Air Force Base track on 1 August 1983 stands out (Fujita, 1990); it shows a highly transient character and a gust peak of $149 \mathrm{mph}$. The wind speeds measured during the NIMROD and JAWS projects were also relevant: 67 and $82 \mathrm{mph}$, respectively, with an estimated yearly probability of $10^{-5}$. Fujita noted that these values are less than those of tornadoes; since microbursts are more frequent and have a larger range, their however, damage can be much greater than that caused by tornadoes. Within the sequence of these outstanding papers, the book Downburst: microburst and macroburst Fujita (1985) occupies an prominent position. It is a milestone for atmospheric sciences.

Since the 1990s, scientific research in this sector has become more and more abundant. Just quoting only the most remarkable topics, it deals with general issues (Brooks et al., 2003; Lompar et al., 2018), thunderstorms affecting more or less wide geographical areas (Geerts, 2001; Gunter and Schroeder, 2015), and single events addressed as case studies (Hirth et al., 2008; Pistotnik et al., 2011).

\section{Wind Speed Recording}

The research illustrated in section Causes, Morphology and LifeCycle of Thunderstorms depicts the atmospheric scenarios in which thunderstorms and downbursts occur; however, it often fails to provide detailed information on the wind field near the ground, namely in the region of major structural interest.

From the end of the 1990s, wind engineering realized that thunderstorm events cause wind velocities often greater than the ones due to synoptic storms, and the design wind speed for regions outside of cyclones is often associated with thunderstorms. Hence, a new line of research aiming to assess monitoring networks suitable for detecting thunderstorm outflows was born. The rapidity with which such events occur requires the measurements be performed with high sampling rates. The study of recordings is inevitably linked to the criteria with which they are interpreted in the light of analytical models (section Analytical Models).
Choi (2000, 2004) and Choi and Hidayat (2002b) illustrated the measurements performed in Singapore at the Changi International Airport and at the Tengah wind-field meteorological stations. These analyses were complemented by the study of some events recorded at the Nanyang Technological University and at the meteorological station of Tuas, where a $150 \mathrm{~m}$ high tower measured the wind at five levels. Records were separated into thunderstorms and monsoons. During thunderstorms, the wind speed profile strongly depended on the anemometer position with respect to the downdraft axis.

Geerts (2001) described the regional climatology of intense gusts related to thunderstorms detected by 10 meteorological stations in New South Wales, Australia. In a period between 20 and 33 years, 123 thunderstorms were recorded with a gust peak between 20.5 and $42 \mathrm{~m} / \mathrm{s}$. Analyses also provide an interpretation of the most suitable indices to predict the events recorded (section Thunderstorm Precursors).

The measurements carried out at the Texas Tech had a key role in wind engineering, since the first representative models of the thunderstorm outflows came from them (Chen and Letchford, 2004a, 2005, 2006, 2007; Holmes et al., 2008). The first recordings (Orwig and Schroeder, 2007) were part of the 2002 Thunderstorm Outflow Experiment carried out at Reese Technology Center in Lubbock. It involved seven towers between 3 and $15 \mathrm{~m}$ high and $263 \mathrm{~m}$ apart, spanning a total distance of $1,578 \mathrm{~m}$. Two relevant cases were recorded with gusts above 30 $\mathrm{m} / \mathrm{s}$ : a rear-flank downdraft of a supercell and a derecho, namely a widespread convectively-induced straight-line storm generated by a mesoscale convective thunderstorm.

Duranona et al. (2006) studied 11 non-synoptic events detected along the Northern European coasts. Jarvi et al. (2007) investigated the characteristics of a microburst that occurred in Southern Finland. Rowcroft (2011) illustrated the results of an experimental campaign conducted through instruments placed between 10 and $80 \mathrm{~m}$; analyses were based on more than 20 years of data acquired in coastal and isle areas of Australia and New Zealand; it was said that one thunderstorm outflow reached a speed of almost $90 \mathrm{~m} / \mathrm{s}$.

Lombardo et al. (2014) continued the measurements carried out at the Texas Tech in the period of 2003-2010. Data were collected mainly at the Wind Engineering Research Field Laboratory (WERFL), thanks to a 50-m tower instrumented at five levels; in 2006 WERFL moved to the Reese Technology Center, $15 \mathrm{~km}$ from Lubbock, where there was a $200-\mathrm{m}$ tower instrumented at 10 levels.

Huang et al. (2015a) used a wireless high-frequency anemometer instrumentation in Yunnan, China, to detect winds and thunderstorms in remote and difficult to reach regions. Iwashita and Kobayashi (2019) described a weather station, POTEKA, installed in Japan in order to create a dense ground surface observation network with a resolution of $\sim 2 \mathrm{~km}$; from 2013, 11 cases of downbursts and damaging winds were detected and their scales were estimated. In addition, the evolution of the main meteorological parameters during the passage of the gust fronts was clarified.

It is apparent that only the use of dense and high-resolution meteorological stations can provide the scientific community 
with data suitable for interpreting, classifying, and modeling downbursts. Taking into account the burdens and time needed for these realizations, it seems essential to start a parallel process aimed at transforming the acquisition systems of existing stations so that these too can in future produce the data necessary to study both synoptic and non-synoptic winds.

\section{Damage Survey}

The study of the damage due to thunderstorms is an effective indirect tool for localizing such events and assessing their intensity, especially in the absence of instrumental data (Fujita, 1985).

Just due to the limited measures available in Romania, Calotescu (2018) used mass-media reports to gather a catalog of wind-induced damage; it aimed at reconstructing a historical series of downbursts and identifying the best locations for the installation of instruments to detect thunderstorms. Iwashita and Kobayashi (2019) performed wind measurements and damage surveys to recognize the scale of the downbursts that occurred since 2013 in the Gunma and Saitama prefectures of Japan. Since Brazil's territory recently exhibited a huge potential to produce severe weather conditions and destructive thunderstorms, Loredo-Souza et al. (2019) provided an overview of the areas with a major risk of downburst occurrence and a survey of the damage due to these phenomena.

The damage to buildings is mainly located at the roof level and concerns roof tiles, steel sheet roofing, purlins and partial or overall roof lift-off. It includes also cladding and facades. Several cases of complete destruction of dwellings have been reported in the country side, mainly for buildings not designed with reference to engineering rules. Stronger storms also produce the partial or total collapse of high, medium and low power transmission towers and in all instances of power lines. Damage have been also reported for warehouses, electricity poles, wooden telephone poles, road sign structures and signboards, agricultural structures, canopies, stands and cranes (Figure 3). Creating a link between wind measurements and damage depending on the structural type is a key step to develop risk analyses based on territorial hazards and built environment vulnerability.

\section{WIND SPEED STATISTICS AND CLIMATOLOGY}

The research on wind statistics and climatology is aiming to evaluate the design wind speed and to forecast thunderstorms, or at least the atmospheric conditions in which they are most likely to occur. This topic may be traced back to four research lines: the extraction of outflow records from a dataset of wind measures (section Extraction of Thunderstorm Outflows), extreme wind speed statistics (section Extreme Wind Speed Statistics), thunderstorm precursors (section Thunderstorm Precursors), and climate changes (section Climate Changes).

\section{Extraction of Thunderstorm Outflows}

To study the statistics and climatology of thunderstorm outflows, it is necessary to use a dataset of phenomena that are initially embedded and even hidden in a broad dataset from which they are to be extracted. Aiming their analysis to statistical purposes, this presumes the knowledge of a rich and complete sequence of thunderstorm outflows. This requirement excludes that such an extraction may involve a detailed and prohibitive assessment of the atmospheric scenarios linked with single records of a dataset and calls for a fast and automated selection procedure.

Kasperski (2002) advanced the idea that in temperate climates at the mid-latitudes thunderstorms cannot be easily separated from frontal synoptic depressions due to the existence of a set of events, called gust fronts, with intermediate properties; he also proposed a rapid criterion to subdivide the data belonging to different events based on their gust factor. Its application is strongly conditioned by the format and quality of available measurements. Lombardo et al. (2009) separated thunderstorm from non-thunderstorm records through an automated criterion applied to the data recorded by the ASOS network in the U.S.; it relies on codes that identify the beginning and end of thunderstorms. Duranona (2015) extracted severe convective events that take place in Uruguay using temperature drops, abrupt wind direction shifts, and pronounced wind speed peaks. Vallis et al. (2019) separated intense wind events into nonsynoptic, synoptic, and suspect, using surface data including wind speed and direction, temperature, atmospheric pressure and, when available, weather conditions.

\section{Extreme Wind Speed Statistics}

Research on extreme wind speed statistics began when Thom (1968a) dealt with mixed populations including extra-tropical and tropical cyclones by distinct distributions combined invoking statistical independence. Thom (1968b) himself showed that a large amount of the yearly peak wind speeds in the U.S. happened during thunderstorms.

The turning point occurred when Gomes and Vickery (1976) studied extreme wind speeds in Australia by separating thunderstorm from non-thunderstorm winds. For each of them they determined distinct distributions and a mixed distribution (Figure 4) later generalized to other wind phenomena dealt with as independent (Gomes and Vickery, 1977/1978). A similar approach was set by Riera et al. (1977). Analogous methods, applications, or refinements were developed by Riera and Nanni (1989), Twisdale and Vickery (1992), Holmes (1999), Choi (1999), Choi and Tanurdjaja (2002), and Cook et al. (2003). Mason (2015) formulated a method for estimating the regional windstorm occurrence frequency based on coupling observational and global reanalysis data. Mohr et al. (2017) analyzed 23 years of measurements detected by 110 stations of the German Weather Service, providing a statistical characterization of thunderstorm outflows' wind speed in Germany. Lombardo and Zickar (2019) inspected thunderstorm near-surface wind measurements in the U.S., producing non-directional and directional statistics based on clusters and a preliminary U.S. map of severe convective events.

An alternative line of research is inspired to the formulation of downburst models whose parameters-downdraft diameter, touch-down position, translation velocity and direction, duration, and frequency of occurrence-are random variables described by joint-probability distributions. Li (2000) studied 

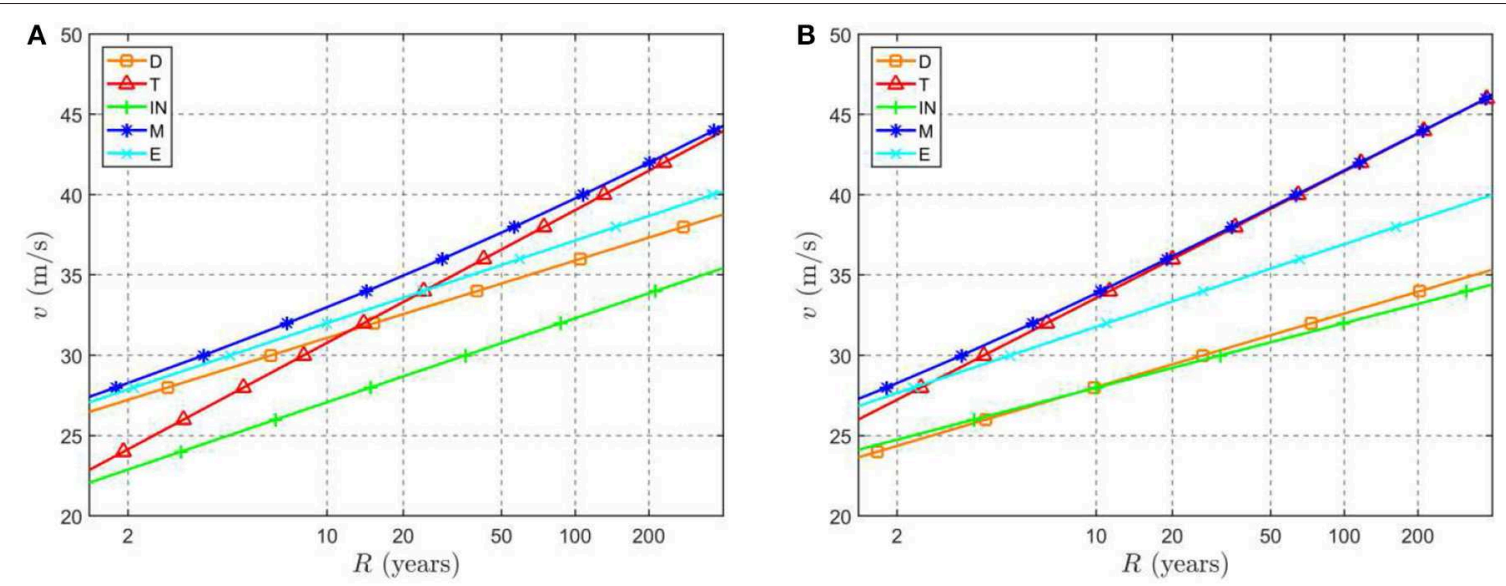

FIGURE 4 | Peak wind velocity as a function of the return period: (A) Port of Livorno; (B) Port of La Spezia (D: Depression; T: Thunderstorms; IN: Intermediate events; M: Mixed distribution; E: Ensemble distribution). Reproduced from Zhang et al. (2018b) with permission from Elsevier.

the probability that a transmission tower was struck by a downburst; Oliver et al. (2000) performed an analogous study for transmission lines. Ponte and Riera (2010) took up a previous thunderstorm model (Ponte and Riera, 2007) and first embedded it into a Monte Carlo simulation strategy aiming to generate long-term synthetic records, in a spirit close to the one long used for tropical cyclones (Georgiou et al., 1983; Vickery et al., 2009). Aboshosha et al. (2017) used a conceptually similar method to study thunderstorm wind speeds at two weather stations in Lubbock and Seattle-Tacoma; the comparison with the statistical analysis of measured data is encouraging.

The author maintains that the use of a Monte Carlo simulator joined with a robust downburst model and data actually representative of this phenomenon constitutes the future of research in this topic.

\section{Thunderstorm Precursors}

Since it is still very difficult, if not impossible, to predict atmospheric phenomena of a limited size and short duration such as downbursts, scientific research has long been oriented toward the definition of precursors, indexes, or indicators of the thermodynamic weather scenarios that provide elements to judge the possible occurrence of these events.

Showalter (1953) stated for the first that "a stability index is an extremely simple, thermodynamic sound and easily understood tool for making a very rapid check on thunderstorm possibilities." According to Galway (1956), such an index was a quantity expressing the potential for convective storm activity. From this came an almost unlimited series of elementary indices-Showalter Index (Showalter, 1953), Lifted Index (Galway, 1956), CAPE (Moncrieff and Miller, 1976), WINDEX (McCann, 1994), SWEAT, Total Totals, K Index, Bulk Richardson number, or their combinations aimed at improving the prediction of thunderstorms in specific geographical areas-Cyprus (Jacovides and Yonetani, 1990), Switzerland (Huntrieser et al., 1997), Australia (Geerts, 2001), The Netherlands (Haklander and Van Delden, 2003), Germany
(Kunz et al., 2009), South Africa (De Coning et al., 2011), and Iran (Tajbakhsh et al., 2012).

\section{Climate Changes}

There is wide evidence that global warming should increase convective potential energy by warming the Earth's surface and creating more moisture in the air through evaporation. On the other hand, a relevant warming in the Arctic should reduce the wind shear in mid-latitude areas prone to severe thunderstorms. These factors give rise to opposite trends and effects stimulating research to develop climate models that help recognize which of them will dominate climate changes. These studies are often strictly linked with the study of thunderstorm precursors and their evolution (Del Genio et al., 2007; Trapp et al., 2007, 2009; Brooks, 2013; Diffenbaugh et al., 2013; Allen et al., 2014; Nissen et al., 2014; Prein et al., 2015; Púcik et al., 2017).

It is largely agreed that the warming of Earth's surface favors convective activity at the base of thunderstorms and this is why their number is increasing. Accordingly, it seems reasonable to assume that such an increase entails, at least statistically, an increase in maximum wind speed. Although available measurements, relative to a period of time incomparable with the time scale of climate changes, cannot be used to support this trend, compared to the last century they show the increase of the number and intensity of thunderstorms. It is possible, if not probable, that this also largely depends on the fact that tools and acquisition techniques normally adopted in the past were not suitable for recording these events.

\section{WIND MODELING AND SIMULATION}

Downburst modeling and simulation may be traced back to four lines of research associated with the sections Analytical Models, Laboratory Tests, CFD Simulations, and data driven Techniques.

\section{Analytical Models}

The first analytical models derived from the application of basic fluid dynamic equations to steady flows aimed at deriving simple 
expressions of the vertical and radial components of wind speed. They often made recourse to re-elaborating and interpreting field measurements, laboratory tests, and CFD simulations. This originated the impinging wall jet and vortex ring models.

The impinging wall jet model originated from Glauert (1956), who formulated the theory of plane and radial jets, both laminar and turbulent, without regard for downbursts. For laminar jets he derived a complex analytical solution; for turbulent jets the solution, even more complex and controversial, gave rise to a wide scientific debate and several simplified solutions (Xu et al., 2008). Oseguera and Bowles (1988) stated the first analytical three-dimensional model of downbursts inspired by Bakke's theory. It started from Euler and continuity equations for an axisymmetric flow around the stagnation point, then introduced shape functions that matched the Terminal Area Simulation System (TASS) model formulated by Proctor (1987a,b), using the results of JAWS and NIMROD projects and laboratory tests carried out by the impingement jet technique on a flat surface.

The ring vortex model originated from Zhu and Etkin (1985), who schematized the downburst as a vertically directed jet against the ground surface; the wind field was obtained from the equations of the motion of ideal fluids, reproducing the boundary wall by creating an image of the specular flow with respect to the ground. Authors noted that experimental data showed a ring vortex at the leading edge of the flow that their model did not take into account. This shortcoming was overcome by Ivan (1986), who formulated an axisymmetric model of the wind speed, called ring vortex model, calibrated on the data of the JAWS project; this model considered a primary vortex above the ground and its mirror image, ensuring that the flow did not pass through the boundary. Schultz (1990) developed a multiple vortex wind model made up of multiple vortex rings, each of which was modeled by means of a vortex ring filament obtained by potential flow theory. Vicroy $(1991,1992)$ studied three analytical models produced by TASS to derive the vertical speed in the downdraft using the horizontal speed in the radial outflow: they are known as linear, empirical, and ring vortex models. Developing the latter one, he obtained a vertical profile of the wind velocity that is among the most cited in literature.

Wood and Kwok (1998) proposed another successful empirical model of the vertical profile of the radial wind velocity calibrated by laboratory tests and CFD simulations. Holmes and Oliver (2000) gave renewed impulse to the impinging jet model, proposing a simplified expression of the radial component of the wind velocity depending on the distance from the jet axis and the time elapsed from the beginning of the downburst; they also expressed the horizontal speed as the vector sum of the stationary radial speed and the translation or background wind speed. This definition presupposes identity between the background synoptic flow speed and the translational component of the thunderstorm cell, a fact that appears anything but obvious.

Li et al. (2012) and Abd-Elaal et al. (2013a) proposed analytical models of the vertical and radial profiles of the horizontal and vertical components of the wind velocity taking into account the non-linear growth of the surface boundary layer through shape functions derived from CFD simulations.
Abd-Elaal et al. (2013b) noted that the difference between downburst recordings often depended on the position and time in which the downdraft touch-down occurred and on its translation speed and direction. From here, they implemented a coupled parametric-CFD model whose parameters were obtained from measurements through an optimization procedure.

Also, Jesson and Sterling (2018) formulated a parametric downburst model; inspired by Ivan (1986), it involves the superposition of three independent fields: the main outflow from the downdraft, the primary ring vortex, and the secondary vortex. The three components of the flow field derived from laboratory tests and CFD simulations performed by Mason et al. (2009). It was noted that the primary vortex becomes elliptical and weakens over time, lifting from the ground. The secondary vortex forms at the leading edge of the primary vortex, at ground level, but is lifted by the rotation of the latter.

A turning point in analytical modeling of downbursts happened when Choi and Hidayat (2002a) expressed the wind speed as the sum of its time-varying mean part, averaged on a moving period between 10 and $120 \mathrm{~s}$, plus a zero mean fluctuation schematized as a stationary process.

This model was improved by Chen and Letchford (2004a, $2005,2006,2007)$ and Chay et al. $(2006,2008)$, who defined the time-varying mean part of the wind speed as the product of a space function-defined according to Oseguera and Bowles (1988), Vicroy (1992), and Wood and Kwok (1998) —and a slowly varying time function. The latter took into account the condition according to which the mean part of the speed was the vector sum of the radial component of the downdraft and its translational component. The combination of the radial and translation parts of the speed was based on Holmes and Oliver's (2000) model. The fluctuation, schematized as non-stationary, is the product of its time-varying standard deviation by a stationary Gaussian process, called reduced turbulent fluctuation, with zero mean and unit standard deviation. A discussion was also provided on the spectral content and the coherence function of the fluctuations.

Taking a leaf from these studies, two new lines of research were pursued.

The first, aiming to define the best methods to separate the moving average wind speed from the residual fluctuation, was opened by Xu and Chen (2004), who used Empirical Mode Decomposition, and Chen and Letchford (2005), who used Wavelet shrinkage. McCullough et al. (2014) evaluated separation methods with reference to turbulence properties. Su et al. (2015) provided an extensive discussion on the requirements that make this operation correct.

The second line aims to develop non-stationary models of thunderstorm outflows and to inspect their properties in the mixed time-frequency domain. The use of the EPSD was discussed by Chen and Letchford (2004a, 2006), Chen (2008), and Kwon and Kareem (2009). Huang and Chen (2009) and Huang et al. (2015b) jointly applied EPSD and Wavelet transforms. Peng et al. (2018) introduced a model to represent evolutionary coherence.

In the framework of these pieces of research, many aspects emerge to be clarified. In particular, they concern the evolution of the profile of wind speed over time, the reliability of vector sum to 
recompose this field, the interaction between the downdraft and the background wind, and the shape of the PSD of the reduced turbulence according to methods used to separate the mean from the residual fluctuation.

\section{Laboratory Tests}

Laboratory tests can be classified into three families. The first and second ones need ad hoc facilities and correspond to fluid release and impinging wall jet experiments. The third one collects the tests in which a traditional wind tunnel is equipped with devices aiming to reproduce thunderstorm-like outflow conditions.

Fluid release tests involve the creation of density or gravity currents (Middleton, 1966) by releasing a liquid mass into a less dense liquid; this allows the simulation of buoyancy and leads to the classic ring vortex, allowing the study of the morphology and physics of thunderstorm outflows. Simpson $(1969,1972)$ first noted that the geometry of frontal regions and up-currents ahead of outflows was similar to that of thunderstorms. Charba (1974) gathered the storm measurements detected by the U.S. National Severe Storms Laboratory and by the WKY-TV transmission tower ( $444 \mathrm{~m}$ tall) to examine the physics of the mass of cold air generated by a gust front and compared it with gravity currents. Subsequent research was carried out by Lundgren et al. (1992), Alahyari and Longmire (1995), and Yao and Lundgren (1996), who showed that simulations were adherent to the physics of microbursts and reproduced the ring vortex and divergent flow well. The small geometric and velocity scales of these tests are usually not appropriate for determining the wind loading of structures.

The impinging wall jet technique is the most widespread laboratory test aimed at reproducing a downburst. During these tests, a jet impinges on a flat surface to create a wall radial outflow and a vortex ring. The first impinging wall jet tests were carried out by Bakke (1957) and Poreh et al. (1967) to study through experiments the theory by Glauert (1956). Advancements on these tests were documented by Donaldson and Snedeker (1971), Launder and Rodi (1983), Didden and Ho (1985), Landreth and Adrian (1990), Cooper et al. (1993), and Wood et al. (2001). The flow visualization by Didden and Ho (1985), in particular, showed the evolution of the wall-jet boundary layer into a secondary vortex counter-rotating with respect to the primary one; this was caused by the primary vortex and moved downstream in the radial direction. Wood et al. (2001) applied the impinging wall jet technique by laboratory tests and CFD simulations; they also collected several profiles of the mean wind velocity provided by field measurements and other wind tunnel tests and CFD analyses, comparing them with each other and with the empirical formula by Wood and Kwok (1998).

Chay and Letchford (2002) carried out laboratory tests to study the loading caused by a downburst on a cube first using a stationary wall jet, then by utilizing a device for reproducing the downburst translation (Letchford and Chay, 2002). Mason et al. (2005) developed the pulsed wall jet technique to simulate a ring vortex followed by a constant air jet. Mason and Wood (2005) studied the effects of the jet inclination to reproduce a downburst embedded into a background flow (Fujita, 1985). Xu and Hangan (2008) and McConville et al. (2009) discussed the

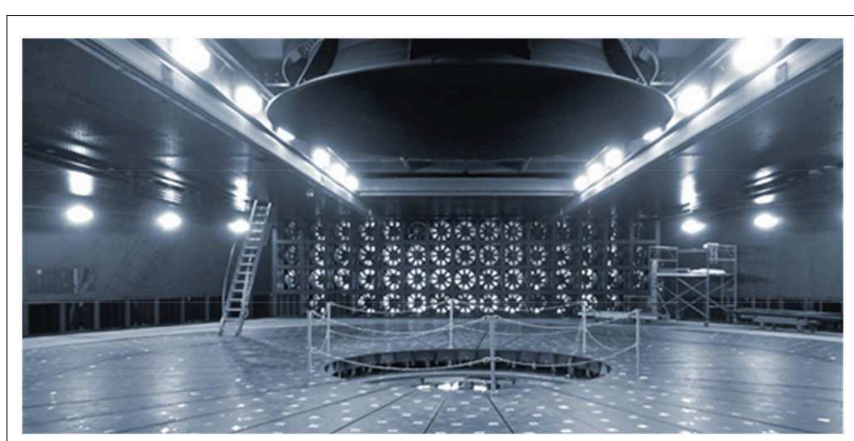

FIGURE 5 | WindEEE Dome test chamber (courtesy Professor Horia Hangan).

crucial issue of the scaling criteria between model experiments and full-scale conditions.

Richter et al. (2018) described the experimental activities carried out at the Karlsruhe Institute of Technology, Germany, to simulate a downburst immersed in a background boundary layer wind flow. Hangan et al. (2017) illustrated the huge potential of the WindEEE Dome (Figure 5) at the Western University, Canada, where a large-scale translating downburst can be embedded into a background boundary layer wind. Romanic et al. (2019) studied the superposition of a straightline wind and a downburst-like outflow, pointing out two dominant scenarios: depending on the relative speeds, the straight-line wind does not produce any significant influence on the impinging flow or modifies this; this remark raises relevant doubts about the correctness of the analytical models based on vector sums to combine wind speeds associated with different phenomena. Junayed et al. (2019) generated many downbursts at the WindEEE Dome, detected the wind fields by Cobra probes and PIV, and compared these with the field measurements of the University of Genova (section Wind and Ports and Wind, Ports, and Sea Projects) and JAWS project; good agreement resulted for the slowly-varying mean speed and turbulence, highlighting some phenomena, especially the primary and secondary vortex, that are not easy to capture in nature.

The third family of laboratory tests collects all the methods by means of which the stationary axial flow in a classic wind tunnel is modified to reproduce thunderstorm outflow conditions. Cao et al. (2002) described the multiple fan wind tunnel laboratory at the Miyazaki University, Japan, built to generate transient and intermittent flows by individually controlled fans. Lin and Savory (2006) illustrated a novel conception in which the radial outflow was simulated by overlapping a slot jet stationary flow onto the flow generated in the open-circuit boundary layer wind tunnel at the Western University. The slot jet flow was made transient by an active gate in front of the slot jet, which produced a roll vortex (Lin et al., 2007). Improvements of this method to simulate ground roughness were reported by Lin et al. (2015). Butler and Kareem (2007) used a pivoted flat plate suddenly rotated in the flow of a wind tunnel to create transient conditions.

Asano et al. (2019) realized a downburst simulator that generates a pulsed jet and a translating downdraft either separately or simultaneously. Le and Caracoglia (2019) examined 
the feasibility of a multi-blade device aiming to reproduce a nonstationary outflow; it was put into the test chamber of a small wind tunnel and its efficacy was evaluated by simulating the Andrews AFB downburst. Aboutabikh et al. (2019) designed and calibrated, also through CFD, a rotating blade system allowing the simulation of downburst outflows; it was conceived for generating the time variations of full-scale downbursts, taking into account the interaction with background flows.

\section{CFD Simulations}

CFD simulations may be led back to full-cloud, sub-cloud, and impinging wall jet models.

Full-cloud models simulate the whole atmospheric region, life cycle, and thermodynamic and micro-physical processes in thunderstorms. The first of these models, created in the 1960s, was based on 2-D numerical simulations (Ogura and Phillips, 1962; Ogura, 1963; Orville, 1965; Liu and Orville, 1969). In the 1970s, the first 3-D numerical simulations were implemented (Steiner, 1973; Miller and Pearce, 1974; Schlesinger, 1975, 1978; Cotton and Tripoli, 1978; Klemp and Wilhelmson, 1978; Clark, 1979). Most of them are conditioned by computational limits and a scarcity of observed data. None of these papers devotes to the wind particular regard with respect to other phenomena occurring during a thunderstorm.

Interest toward downburst simulations increased in the 1980s thanks to the evolution of computing power and the first experimental campaigns. Proctor (1987a,b) developed a 3-D model, Terminal Area Simulation System (TASS), which simulated various phenomena including downbursts, tornadoes, and burst fronts. It was governed by non-hydrostatic and nonstationary equations and the fluid was compressible. Water was divided into water vapor, ice crystals, droplet clouds, rain, snow, and hail, and models that parameterize phase changes were used. TASS explicitly simulated turbulence scales greater than the solution grid size; minor scales were parameterized by a first order closure. The model incorporated surface stresses as a function of stratification, surface roughness, and local winds. The mesh was free to translate. Input was made up of initial measured or simulated conditions. Output included the 3-D field of all meteorological parameters. An extensive comparison with measured data was also provided. Similar or advanced full-cloud models were set by Hjelmfelt et al. (1989), Knupp (1989), and Straka and Anderson (1993).

Nicholls et al. (1993) first used LES to evaluate the wind loading of a building due to a downburst; since full-cloud models simulate the whole thunderstorm without focusing on near-ground flows, they adopted a multi-scale 3-D model, showing that buildings are sensitive to the whole structure of the downburst. Orf et al. (2012) applied a full-cloud model to perform a 4-step analysis: (1) CFD simulation of the downburst; (2) comparison between full-cloud analyses and simplified subcloud and impinging wall jet models; (3) study of the influence of local parameters such as temperature, humidity, roughness, and topography; (4) coupling of the downburst model with a structural model of transmission lines. They concluded that future numerical advancements will allow for also using fullcloud models in wind engineering applications.
Sub-cloud models fail to simulate the whole thunderstorm field to focus on near-ground flows, namely the domain of engineering interest. They are driven by a forcing, typically of a microphysical nature, often imposed in a high region of the domain, which simulates the downburst, or part of it. This concept was introduced by Mitchell and Hovermale (1977), who created a thermal forcing under the thunderstorm cloud, which simulated the cooling processes of microphysical nature, giving rise to a cold downdraft. Srivastava (1985) developed a monodimensional model of the downdraft taking into account all the physical parameters that affect this phenomenon.

Droegemeier and Wjlhelmson (1987) proposed a 2-D numerical model that simulated a thunderstorm outflow imposing a controlled horizontal flow of cold air entering the computational domain through a side contour. Still in the framework of the TASS program, Proctor $(1988,1989)$ created a downdraft by assigning a distribution of the precipitation at the top boundary, allowing it to fall in the domain; he proved that the intensity of a microburst depends on the vertical distribution of temperature and humidity, the horizontal amplitude of precipitation and downdraft, and the intensity, distribution, and duration of precipitation. Anderson et al. (1992) and Orf et al. (1997) generated a downdraft by a time- and space-dependent cooling function that forced the thermal field of the model. Orf and Anderson (1999) studied traveling microbursts with a sub-cloud model.

Mason et al. (2009, 2010) applied a thermal forcing and a non-hydrostatic model to study stationary and non-stationary downbursts (Figure 6); equations were solved by URANS approximation and closed by a SAS turbulence model. Because of the time-averaging involved in URANS, simulations provided a picture of the macro-scale wind field, and thereby the slowlyvarying mean speed. Vermeire et al. (2011a) used the cooling source model by Anderson et al. (1992) to study one and two downbursts by LES. Oreskovic et al. (2018) used LES in a cooling source model to investigate the influence of the geometrical and thermal parameters governing the thunderstorm downburst outflow; significant variations are found by varying the cooling source shape, size, aspect ratio, and height.

The impinging wall jet models simulate impinging wall jet laboratory tests; like sub-cloud models, they forgo simulating the whole thunderstorm cell to focus on the near-ground flow; differently from sub-cloud models, the forcing source is not thermal but mechanical.

This technique was first applied to downbursts by Selvam and Holmes (1992), who used a 2-D model to simulate a downdraft current as a jet of incompressible air perpendicular to a plane; Navier-Stokes equations were combined with a $\mathrm{k}-\varepsilon$ model to simulate turbulence. Their results reasonably matched Bakke's laboratory tests (1957) and Fujita's observations (1990), but showed some differences from the TASS program (Proctor, 1988). Wood et al. (2001) solved Navier-Stokes equations with two turbulence models: $\mathrm{k}-\varepsilon$, which approximated turbulence by an eddy viscosity model, and DSM, which determined all the components of the Reynolds tensor; DSM provided a closer similarity between small and large-scale simulations. Other CFD analyses of the impinging wall jet type were carried out by Chay 

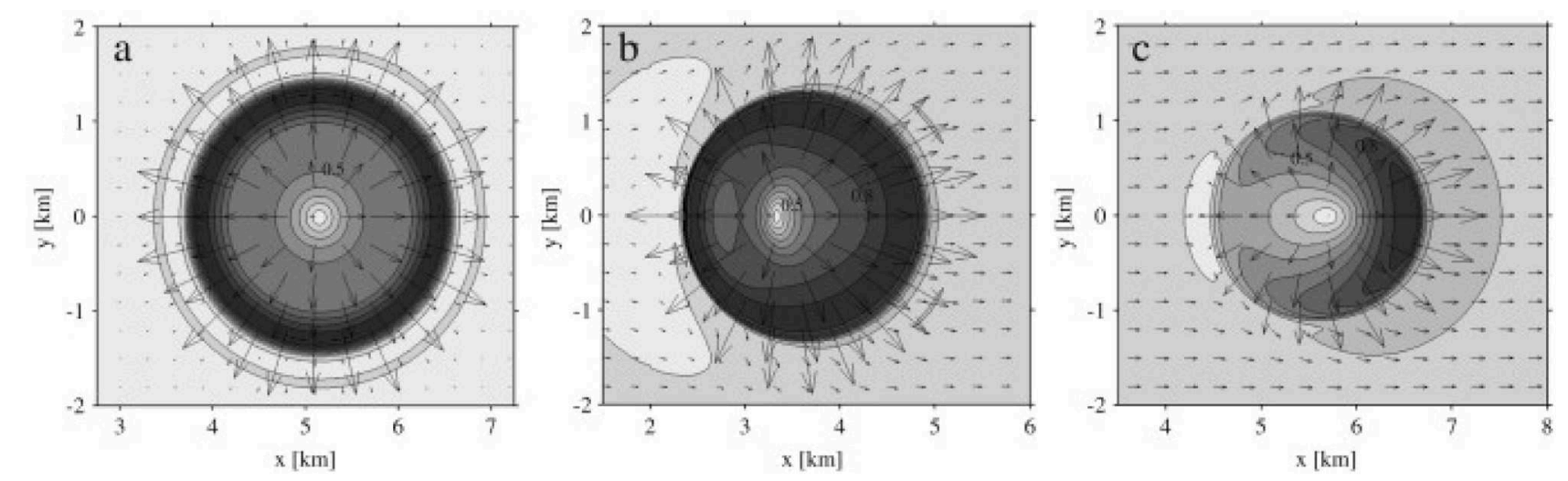

FIGURE 6 | Horizontal $z=10$ m velocity contour and vector plots at the time of the storm maximum velocity: (A) stationary downdraft. (B, C) non-stationary simulations. Reproduced from Mason et al. (2010) with permission from Elsevier.

et al. (2006), using a k- $\varepsilon$ model, by Kim and Hangan (2007), through URANS, and by Sengupta and Sarkar (2008), who applied and compared different models, namely k- $\varepsilon$ standard,

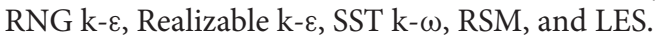

Vermeire et al. (2011b) used LES to study the outflow at the ground for various roughness lengths; analyses were carried out by the cooling source and impinging jet methods, comparing results with meteorological observations. Zhang et al. (2013a) also applied the cooling source and impinging jet methods by URANS, comparing their results with laboratory tests carried out by an impinging wall jet and field measurements detected during NIMROD and JAWS projects. Aboshosha et al. (2015) used the impinging jet method and LES to inspect turbulence properties on varying roughness length.

Oreskovich et al. (2018) discussed advantages and disadvantages of using full-cloud, cooling source, and impinging jet methods by CFD, then carried out large-scale numerical simulations of downbursts aiming to develop a simple model that replicated the key physical parameters whilst maintaining the relative simplicity of the impinging jet model. This aim was pursued by LES in the framework of a full-cloud model incorporating a sub-grid turbulence model and micro-physics parameterizations.

In the framework of an impressive amount of papers, a limited number of studies aimed at comparing different computational methods stands out, as well as an almost total lack of comparisons among the results of these methods, large-scale laboratory tests, and field measurements.

\section{Data Driven Techniques}

Starting from analytical models, laboratory tests, and CFD simulations, a lot of research has been carried out to generate transient wind fields by data driven techniques such as Monte Carlo methods.

The first applications (Chen and Letchford, 2004b, 2007; Chay and Albermani, 2005; Chay et al., 2006) used ARMA models to simulate the stationary Gaussian field of the reduced turbulence (section Analytical Models). This implies the subsequent re-composition of the global transient wind field.

From the 2010s, several methods were developed to simulate the non-stationary wind velocity field in its whole. Wang et al.
(2013) proposed a data-driven method to simulate downburst wind speeds by Hilbert transform, stationary wavelet transform, and POD. Huang (2014) used wavelet and spectral representation to simulate a multivariate non-stationary process starting from an EPSD matrix with real and complex coherence matrix independent of time. Xu et al. (2014) advanced a conditional simulation method. Wang et al. (2014) proposed a simulation algorithm based on Hilbert and Wavelet transforms. Huang et al. (2015b) used discrete wavelet transform and kernel regression to define the time-varying mean and standard deviation of nonstationary wind speeds; then, based upon the estimated EPSD, they studied the transient properties of non-stationary winds.

\section{WIND LOADING OF STRUCTURES}

The study of the wind loading of structures due to thunderstorm outflows gave rise to two research lines. The first, not necessarily related to downbursts, is addressed to the section Fundamentals of Transient Aerodynamics. The second, strictly related to downburst wind loading of structures, is based on laboratory tests, CFD simulations, and full-scale measurements (section Bluff-Body Transient Aerodynamics).

\section{Fundamentals of Transient Aerodynamics}

Despite the importance of transient aerodynamics with regard to thunderstorm outflows and their loading of structures, the research devoted to investigating this topic is still limited and fragmentary.

Sarpkaya (1963) studied the drag and lift coefficients of a circular cylinder on varying the flow velocity. Sarpkaia (1966) himself developed experimental tests where a device allowed a rapid growth of the flow speed from zero to a steady value; experiments were performed on a circular cylinder and a flat plate, with the results showing that during the speed increase the drag coefficient exceeded by about $25 \%$ that of a steady condition. The phenomenon was dominated by the displacement of the separation points, which reached a steady condition after a long time. Sarpkaya and Ihrig (1986) proved that the overshooting of the alongwind and crosswind force may be modified through small changes of the body shape or the angle of attack. 
Okajima et al. (1997) studied the aerodynamic coefficients of cylinders with circular and square cross-sections in nonstationary oscillating flows. Katsura (1997) analyzed the aerodynamic actions of the growth of the flow speed from zero speed to a steady condition; some applications relating to the pressure field on a model dome were also conducted. Tamai et al. (2001) continued this research by conducting full-scale experiments at the Shionomisaki Wind Effect Laboratory of Kyoto University. Matsumoto et al. (2007) performed wind tunnel tests aiming to measure the drag force on circular and rectangular cylinders subjected to a sudden increase of the speed achieved by a shutter; this phenomenon was described by indicial functions. Takeuchi et al. $(2008,2012)$ studied the overshoot of aerodynamic forces due to sudden gusts. Shirato et al. (2009) investigated the transient drag force induced by a sudden growth of the wind speed during wind tunnel tests on 2-D rectangular cylinders with various aspect ratios. The moment in which the drag reaches its maximum depends on the aspect ratio; the time delay with which the windward and leeward faces approach the quasi-steady condition play an important role on the overshoot of the drag force.

Butler et al. (2010) generated a gust front type flow by the multiple fan wind tunnel at the Miyazaki University and investigated the effects of its transient features on bluff-body aerodynamics. Results showed the evolution of the surface pressure over time, highlighting significant differences in respect to the pressure due to boundary layer steady profiles.

Mason et al. (2016) carried out experiments in the actively controlled wind tunnel at the University of Queensland, designed to study the loading of two-dimensional cylinders during rampup events. The influence of non-stationarity on the pressure distribution around the centreline of various bodies was studied, with a focus on the separation-reattachment region. Unlike previous research, these tests did not exhibit any overshoot in drag or lift forces during the ramping up phase; this was attributed to a longer rise time more in line with what is expected during severe convective events.

Continuing this research, Yang and Mason (2019) studied two-dimensional rectangular cylinders in steady and accelerating wind tunnel tests to determine how much aerodynamics is modified by flow acceleration. Also in this case, no overshoot of the aerodynamic load beyond that experienced in steady flows was observed. However, remembering the results obtained by Sarpkaya and Ihrig (1986), a broader study of body shapes and orientations is required before stating this conclusively.

The problem dealt with in this section is thus completely open and awaiting contributions aimed at clarifying its fundamental aspects.

\section{Bluff-Body Transient Aerodynamics}

The research concerning 3-D bluff-body aerodynamics is mainly based on laboratory tests and CFD simulations. Recently, some full-scale experiments were also conducted.

The first pioneering laboratory tests were carried out by Chay and Letchford (2002) and Letchford and Chay (2002), who created an impinging wall jet in a wind tunnel.
Stationary analyses described in the first paper (Chay and Letchford, 2002) proved that pressure over a cube depends on the ratio between its distance $\mathrm{X}$ from the jet axis and its side $\mathrm{D}$ : for $\mathrm{X} / \mathrm{D} \approx 0$ a static pressure field occurs; for $\mathrm{X} / \mathrm{D} \approx 0.5$ pressure is caused by the static field and the diverging wall jet flow; for X/D > 0.75 pressure is due solely to the diverging flow. The comparison of the pressure distribution on the cube with traditional wind tunnel tests in uniform and boundary layer flows highlights a similarity with uniform flow tests in the highest pressure region, for $\mathrm{X} / \mathrm{D} \approx 1$; however, windward pressure was greater in the wall jet because the velocity profile decreases with height. For X/D $>1.5$ the outflow assumes a boundary layer shape and pressure becomes like those of traditional boundary layer tests; however, this region exhibits a much lower velocity and pressure.

Non-stationary flows produced by jet translation were analyzed in the second paper (Letchford and Chay, 2002). For translational speeds below $20 \%$ of the downdraft speed, no gust front occurred, and the outflow was similar to the stationary one. Instead, the sudden growth of the wind speed due to the passage of the gust front was replicated for higher translation speeds; in this case the flow field had the shape of a ring vortex and pressure and suction coefficients were larger than in stationary jets. Authors concluded this paper with a prophetic doubt: "it remains to be seen whether it is possible to retain the large database of pressure coefficients obtained in boundary layer flow and apply an appropriate design thunderstorm wind speed profile."

Sengupta et al. (2008) reproduced the impinging wall jet both in a laboratory and by LES to evaluate the wind loading due to stationary and translating downdrafts on a cubic building model. Zhang et al. (2013b, 2014a,b) conducted laboratory experiments by an impinging wall jet to evaluate the flow field in a microburst and the pressure caused on a gable-roof building, on lowrise buildings with different shapes (Figure 7) and on high-rise building models. The actions of the microburst depends on its position with respect to the building: when the building is under the downdraft, the force on the roof is directed downward. The maximum mean and peak wind actions occur when the model is at a distance of about one diameter from the jet axis; when the model is in the outflow region, pressures tend to the ones due to synoptic events. Studies on the internal pressure in a low-rise building subjected to a microburst are described by Zhang et al. (2015).

Jesson et al. (2015) studied the effects of downbursts on low-rise buildings by the impinging wall jet simulator at the University of Birmingham; two building models were investigated-a square-plan flat-roofed structure and a rectangular portal-frame-for different outflow directions $\left(0^{\circ}, 45^{\circ}\right.$, and $\left.90^{\circ}\right)$. The greatest pressure coefficients over the roof occur when it is in the region of maximum outflow speed. Jubayer et al. (2016) conducted similar tests at the WindEEE Dome at the Western.

Takeuchi et al. (2016) used laboratory and CFD simulations with an LES model to study the role of wind direction and roof shape on the pressure overshoot caused on a low-rise building by a short-rise-time gust. Haines and Taylor (2018) simulated an impinging wall jet by LES to inspect the wind loading of 

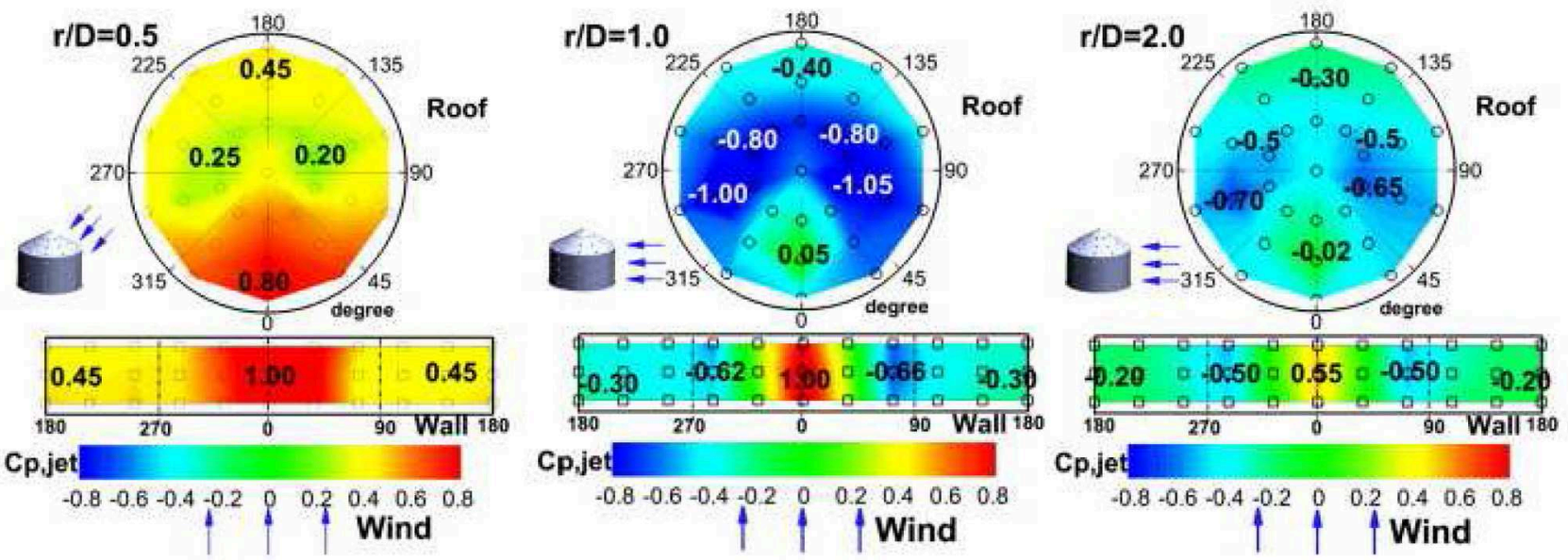

FIGURE 7 | Mean pressure coefficients for a grain bin model. Reproduced from Zhang et al. (2014a) with permission from Elsevier.

low-rise buildings, comparing their results with those obtained from laboratory experiments at the University of Birmingham. Huang et al. (2018) simulated a stationary 3D impinging jet through an SST- $\omega$ turbulence model to inspect the flow structure around a high-rise building model, the pressure distribution, and the aerodynamic loading. Asano et al. (2019) used the laboratory device described in section Laboratory Tests to study the effects of a non-stationary downburst on the wind field and wind loading related to a flat-roofed low-rise building model; the comparison with the results of similar measurements in a turbulent boundary layer flow showed relevant differences.

Lombardo et al. (2018) investigated the wind loading caused by a downburst event that struck the full-scale low-rise building laboratory of Texas Tech University. Like the wind speed, the pressure coefficients displayed clear ramp-up and -down behavior. Comparisons were also conducted with the load measured during synoptic wind events. In every case the definitions of pressure coefficient and reference pressure play a key role.

Finally, a remarkable study from to Iida and Uematsu (2019), first reproduced transient features experimentally using a downburst simulator, then conducted a CFD simulation by LES to investigate the wind loading of a building model. The comparisons between the obtained results exhibit a robust agreement but also point out the key issue of how to define the non-steady pressure coefficients and measure the reference pressure.

Both of these aspects should be prioritized in future studies on transient aerodynamics.

\section{WIND-EXCITED RESPONSE OF STRUCTURES}

The study of the dynamic response of structures to thunderstorm outflows concerns the sections Reference Systems and Real Structures.

\section{Reference Systems}

The study of Single-Degree-Of-Freedom (SDOF), Multi-DegreeOf-Freedom (MDOF), and slender beam models is aimed at depicting the conceptual aspects of structural response, formulating general methods to evaluate it and identifying the role of the parameters on which the response depends.

Choi and Hidayat (2002a) were the first to study the dynamic alongwind response of a SDOF system, aiming to extend the gust factor technique (Davenport, 1961) from synoptic to transient winds. This method was refined by Chen and Letchford (2004b), who called "Maximum Dynamic Magnification Factor" the ratio between the maximum dynamic response and the static response to the peak load, by Holmes et al. (2005), who applied Duhamel's integral to evaluate a "Dynamic Response Factor" defined as the ratio between the equivalent static force and the maximum loading, and by Chay and Albermani (2005), who used ARMA simulations to determine an equally called "Dynamic Response Factor," given by the ratio between the maximum response to a downburst and a stationary wind. All these papers solved the linear equations of motion in the time-domain, schematizing the turbulence as identically coherent in space.

The first frequency domain analysis of the wind-excited response of buildings to non-stationary winds is due to Chen (2008), who expressed the wind loading as the sum of a deterministic mean function, slowly varying over time, and a random fluctuating component, rapidly varying over time. The response was determined in turn as the sum of a static response to the mean wind loading and a fluctuating response expressed by an evolutionary power spectral density (EPSD).

Kwon and Kareem $(2009,2019)$ applied EPSD to extend the gust factor method from synoptic winds to gust fronts. They determined the equivalent static force on a building as the product of the equivalent static force associated to an ABL profile, the gust front factor, and a factor that transforms the ABL shape of the force into the gust front shape. The gust front factor was given in turn by the product of the kinematic effects factor, the pulse dynamic factor, the structural dynamics factor, and the load 
magnification factor. They take into account, respectively, the different profiles of a gust front and an ABL wind, the variation of the mean wind speed, the non-stationary role of turbulence, and transient aerodynamic effects; the discussion on the latter quantity was purely conceptual.

Huang et al. (2013) expressed the non-stationary wind loading by its EPSD and simulated non-stationary loading time histories used to integrate the equations of motion in the time-domain; results were compared with those obtained by Chen (2008). Chen (2015) himself developed a frequencydomain framework to predict the multimodal coupled buffeting response of long-span bridges to non-stationary winds. The timevarying mean, self-excited, and buffeting forces were modeled respectively by static force coefficients, flutter derivatives, and admittances.

Le and Caracoglia (2015a,b) used the Wavelet-Galerkin method to determine the non-linear and/or non-stationary response of SDOF and MDOF systems. Su et al. (2015) analyzed the dynamic response of a tall building by a quasi-static approach for the slowly-varying mean and the pseudo-excitation method for the fluctuating component. Kareem et al. (2016) generalized the Davenport's chain from stationary to non-stationary winds, based on wavelet transforms or EPSD. Le and Caracoglia (2016) studied the crosswind response of a tall building in non-synoptic winds. Wang et al. (2017) found a closed form solution for the buffeting response of a nonlinear double-hinged overhead transmission conductor. Le and Caracoglia (2017) implemented a numerical model of the transient response of a tall building under a digitally simulated downburst consistent with an EPSD schematization. Peng et al. (2018) developed an EPSD approach including a time-varying coherence function.

Contrarily to these complex approaches, Miguel et al. (2018) provided a simple engineering model and several critical remarks on the wind loading of buildings due to thunderstorm outflows. Their study confirmed a result already present in other papers: high-rise buildings are sensitive to extra-tropical cyclones, while low-rise buildings should be designed for downbursts.

Finally, it is worth mentioning a couple of papers addressed to structural safety and performance-based design. Le and Caracoglia (2018) used the Wavelet-Galerkin method to evaluate structural fragility due to downbursts. Caracoglia (2018) combined different features to construct a general model that takes into account the non-stationary response to downbursts, wind-induced damage, and costs related to structural maintenance.

The contributions described above highlight a wide range of formulations aiming to extend classical stationary structural analysis to non-stationary phenomena. The common denominator of these studies is the striking contrast between elegant methods and the lack of data to calibrate and validate these models. Current research at the University of Genoa (section ERC THUNDERR Project) is aimed at filling this gap. It is also worth noticing the persistent lack of detailed codes on thunderstorm loading of structures, except for some preliminary guidelines on a few types of real structures (Section 7.2). The ERC project THUNDERR (Section 8.3) aims at creating the bases to fill this gap in a near future.

\section{Real Structures}

The analysis of real structures mainly focuses on transmission lines and towers, i.e., the structure type that suffers the largest number of collapses and the most extensive damage due to thunderstorms.

A large amount of the research in this sector defined the wind velocity field due to thunderstorms by CFD simulations of the slowly-varying mean wind velocity whose output was transformed into aerodynamic loads applied to FEM. Savory et al. (2001) inaugurated this line showing that towers are usually destroyed by tornadoes whereas downbursts cause the collapse of transmission lines due to their simultaneous actions on towers and conductor spans. Shehata et al. (2005) described the above procedure and compared the results of downburst analyses with those of synoptic winds; this revealed the importance of considering downbursts. Darwish et al. (2010) extracted turbulence from real measurements and added it to the mean wind speed simulated by CFD; dynamic analyses proved that the resonant part of the response is almost negligible due to the large aerodynamic damping of conductors. Darwish and El Damatty (2011) performed a parametric evaluation of the behavior of self-supported transmission line towers to find the critical configurations that cause the maximum axial forces in the members of a tower. Aboshosha and El Damatty (2015) proposed a practical engineering solution to calculate the reactions of transmission line conductors due to downbursts. Aboshosha et al. (2016) reviewed the response of transmission lines, pointing out the limits in structural codes and standards for wind loading.

In the spirit of structural safety, Yang and Hong (2016) and Mara et al. (2016) evaluated the capacity curve of a transmission tower, considering synoptic and downburst winds as well as the interaction between cables and towers; evaluations were carried out by incremental dynamic analysis and non-linear pushover static analysis. El Damatty and Elawady (2018) carried out an extensive parametric analysis of transmission lines to evaluate their critical response to downburst loads; three load cases were identified as critical and the economic impact of designing the system for them was assessed.

The first aeroelastic wind tunnel tests on a transmission line model were carried out at the WindEEE Dome by Elawadi et al. (2017). The comparison between the results with those previously obtained by CFD-FEM showed reasonable agreement (Elawady et al., 2018). The first full-scale measurements of the wind load due to a downburst on an overhead transmission line were performed in Germany by Stengel and Klaus (2017).

\section{RESEARCH ON THUNDERSTORMS AT THE UNIVERSITY IF GENOVA}

As already noted, the above sections exclude the contributions given by the author and his research group. This research was inspired by two European projects-Wind and Ports (20092012) and Wind, Ports and Sea (2013-2015) - during which an extensive wind monitoring network was developed (Section Wind and Ports And Wind, Ports, and Sea Projects). The analysis of recorded data highlighted a large number of transient events 


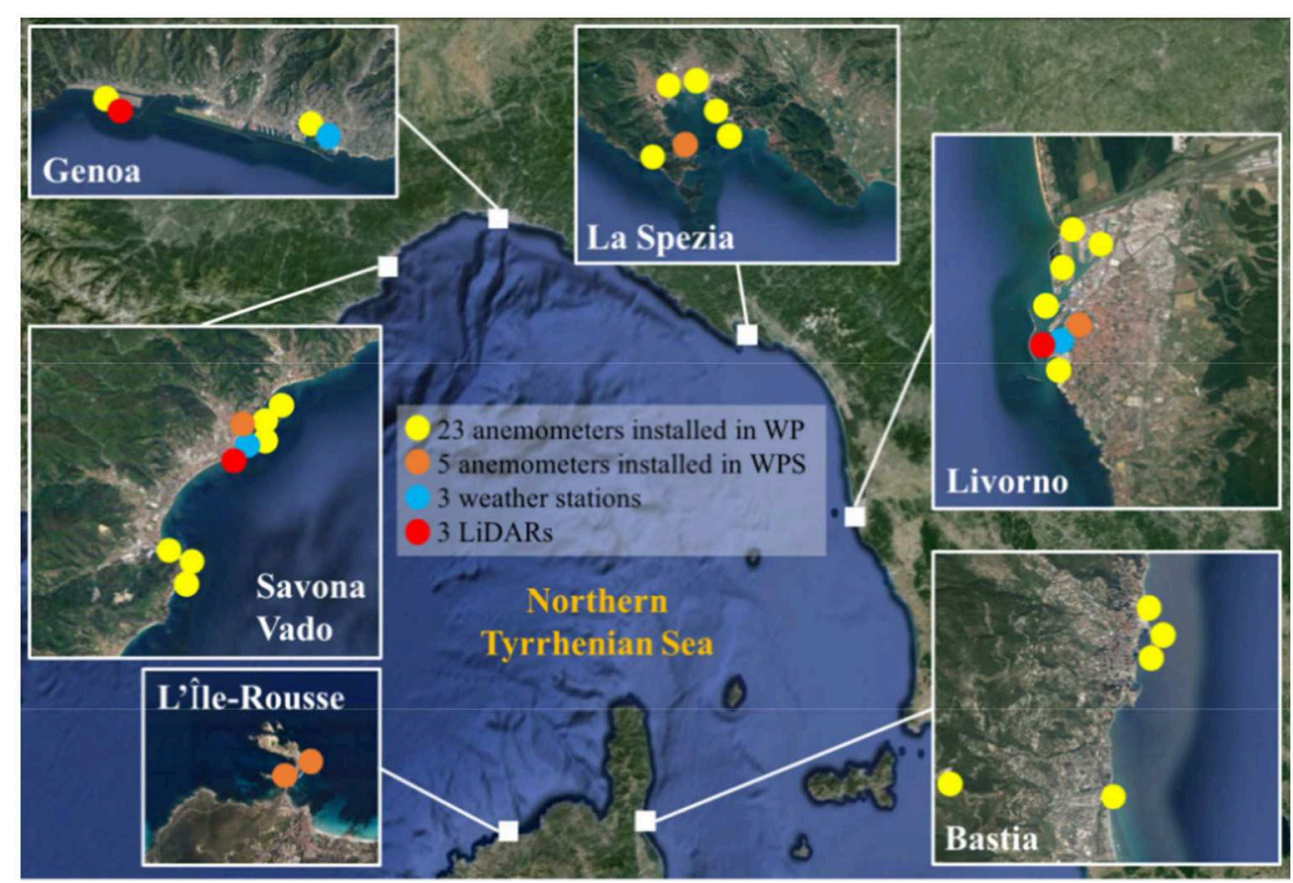

FIGURE 8 | WP \&WPS wind monitoring network. Reproduced from Zhang et al. (2018a) with permission from Elsevier.

and two new research projects were opened-San Paolo (20162018) and PRIN (2016-2019) - to investigate the properties of downbursts and their load of structures (section San Paolo and PRIN Projects). Hence the ERC THUNDERR Project (2017-2022) which aimed to study thunderstorm outflows to design wind-safer and cost-efficient structures (section ERC THUNDERR Project).

\section{Wind and Ports and Wind, Ports, and Sea Projects}

"Wind and Ports" (WP) (Solari et al., 2012) and "Wind, Ports, and Sea" (WPS) (Repetto et al., 2017) are projects supported by European Cross-border program Italy-France Maritime 20072013. They dealt with the safe management and risk assessment of the main ports in High Tyrrhenian Sea. This objective was pursued by creating an extensive wind monitoring network, multi-scale simulation models, medium- and short-term wind forecast algorithms, and wind climate evaluations. Results were transferred to port stakeholders by an innovative Web GIS platform (Repetto et al., 2018).

The WP and WPS monitoring network (Figure 8) includes 28 ultrasonic anemometers, positioned in the Ports of Genoa, La Spezia, Livorno, Savona, Bastia, and L'̂̂le Rousse, three LiDAR profilers, and three meteorological stations, each including an ultrasonic anemometer, a barometer, a thermometer, and a hygrometer.

Most ultrasonic anemometers detect wind speed and direction with a $10 \mathrm{~Hz}$ sampling rate. Sensors are installed on high towers and a few antenna masts on building roofs, at least $10 \mathrm{~m}$ above the ground. LiDAR profilers detect the three components of the wind speed between 40 and $250 \mathrm{~m}$ height, with a sampling rate of $1 \mathrm{~Hz}$. Local servers receive acquisitions in their own port area and send this information to the central server at DICCA, which store them in a database.

\section{San Paolo and PRIN Projects}

Located in an area characterized by intense convective activity and its often dramatic consequences due to floods and winds, the WP and WPS monitoring network generated an unprecedented amount of non-stationary wind speed data due to gust fronts. This inspired two projects, one supported by Compagnia di San Paolo- "Wind monitoring, simulation and forecasting for the smart management and safety of port, urban, and territorial systems"- and the other by Italian Ministry for Instruction, University and Research-"Measurement and representation of wind actions and effects on structures"-during which two main topics were studied: downburst wind field and wind loading of structures.

In the framework of the first topic, a procedure was implemented to separate extra-tropical cyclones, thunderstorm outflows and intermediate winds (De Gaetano et al., 2014), without making recourse to prohibitive meteorological surveys. Non-stationary records were extracted (Solari et al., 2015a; Zhang et al., 2018a) and analyzed to evaluate their properties relevant to wind loading of structures (Figure 9). Research was also performed on the weather scenario associated with the event that occurred in Livorno on 1 October 2012 (Burlando et al., 2017b); the concurrent atmospheric conditions were studied through in-situ measurements, model analyses, remote sensing, proxy 

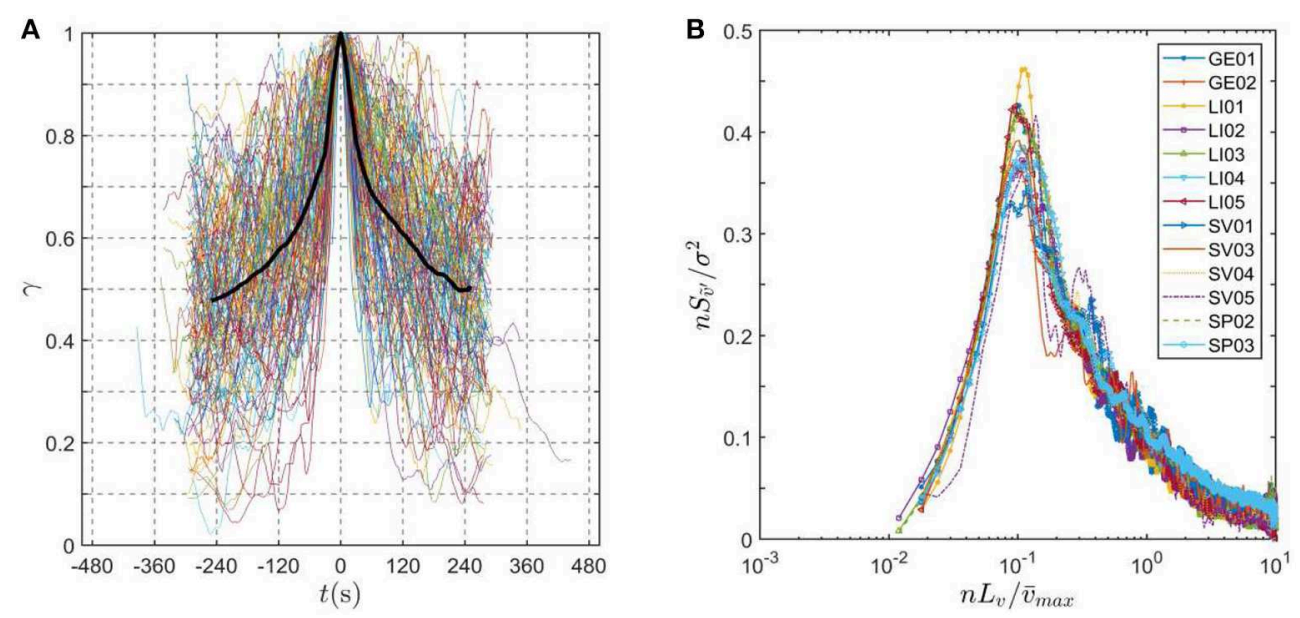

FIGURE 9 | Thunderstorm outflows detected by the WP and WPS monitoring network: (A) slowly-varying mean wind speeds normalised to their maximum and mean value (thick line). (B) mean power spectral density of the reduced turbulence for each anemometer. Reproduced from Zhang et al. (2018a) with permission from Elsevier.

data, and visual observations. Accordingly, the chosen test event was classified as a wet downburst.

As far as the second topic is concerned, the analysis of thunderstorm loading of structures started from the remark that downbursts are transient events and structural response to such events, especially earthquakes, is traditionally determined by response spectrum technique. A "new" method was thus formulated to generalize the "old" response spectrum technique from earthquakes (Housner et al., 1953) and synoptic winds (Solari, 1989) to thunderstorms. Initially, the study was circumscribed to a SDOF system (Solari et al., 2015b) subjected to an identically coherent wind field; it proved that the equivalent static load is the product of the peak wind load by a non-dimensional factor, the thunderstorm response spectrum, depending on the structure fundamental frequency and damping ratio. Later, the formulation was generalized to MDOF systems (Solari, 2016) subjected to partially coherent wind fields modeled by equivalent wind spectrum technique (Piccardo and Solari, 1998); the equivalent static load is the product of the peak wind load by a non-dimensional factor, the equivalent response spectrum, depending on the first frequency, damping ratio and reference structure size. Finally, in order to check this approach, time domain analyses were performed through a novel hybrid simulation procedure (Solari et al., 2017). Integrations of motion equations showed that the density function of the maximum response to thunderstorms is much more spread than the one due to synoptic winds.

\section{ERC THUNDERR Project}

The results provided by the above research were so encouraging as to stimulate the author to apply to the European Research Council (ERC) for an Advanced Grant (AdG) 2016. This led to the project THUNDERR, "Detection, simulation, modeling and loading of thunderstorm outflows to design wind-safer and cost-efficient structures." THUNDERR is an acronym of
THUNDERstorm, which expresses the Roar with which this project aims at creating state-of-the-art innovation in the field. It pursues three objectives concerning thunderstorms, structures, and dissemination.

The first objective deals with the thunderstorm as a physical phenomenon and aims at formulating a unitary and interdisciplinary model for atmospheric science and engineering. In this framework, the WP and WPS monitoring network has been enhanced by a Windcube $400 \mathrm{~S}$ pulsed LiDAR scanning system in the Port of Genoa (Figure 10). It detects wind speed up to a nominal distance of $14 \mathrm{~km}$, with a space step up to $100 \mathrm{~m}$ and a sampling rate up to $1 \mathrm{~Hz}$. It is used to detect the touchdown position and diameter of downdrafts, their direction and translational speed, and the background wind.

Meanwhile, a new wind speed decomposition rule was developed to take in to account the rapid direction changes that frequently occur during a gust front (Zhang et al., 2019a), allowing a unified treatment of the wind speed in synoptic and thunderstorm winds. Studies of the wind speed detected by LiDAR profilers (Burlando et al., 2017a) showed that the noseshaped profile usually lasts for the short phase of the ramp-up of the wind speed. Downburst simulations were conducted at the WindEEE Dome (Hangan et al., 2017) to explore the role of terrain roughness and the combination of the background flow with the downdraft and its translational speed. Parallel CFD simulations are being developed in co-operation with the Technical University Eindhoven (Blocken, 2014) to reproduce laboratory tests. Another co-operation is in progress with Freie Universität Berlin (Nissen et al., 2014) to establish a link between field measurements and weather scenarios (Burlando et al., 2018). Other co-operations with Chinese universities (Huang et al., 2019; Zhang et al., 2019b) aim to compare thunderstorm outflows detected in different parts of the world to answer the question: have downbursts similar properties everywhere, or do they depend on local climatology? Finally, evaluations of the 

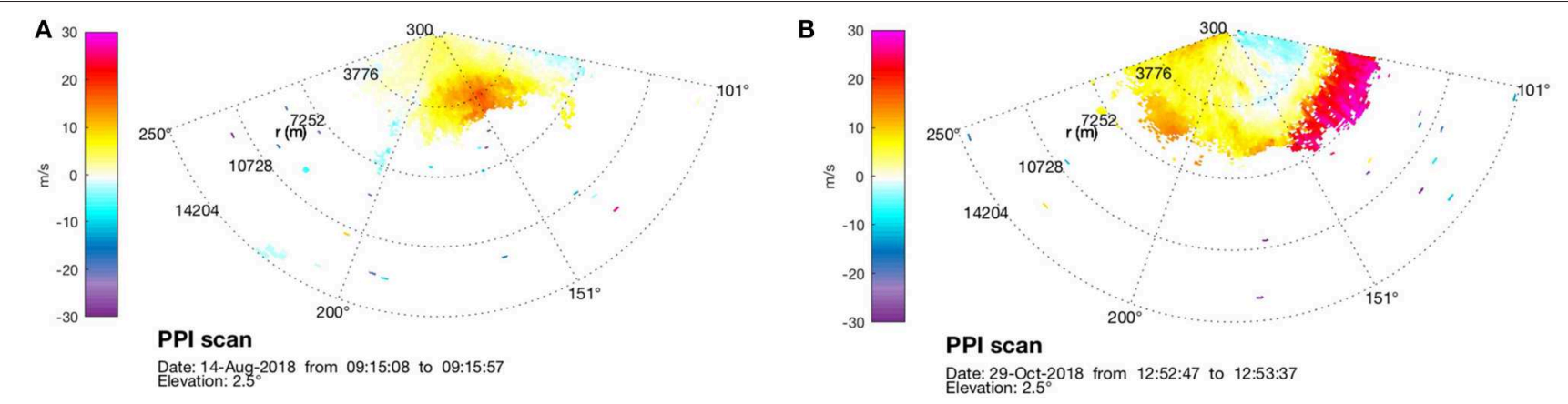

FIGURE 10 | Radial wind velocity measured by the Windcube 400S LiDAR scanner installed in the Port of Genoa: (A) August 142018 ; (B) October 292018.
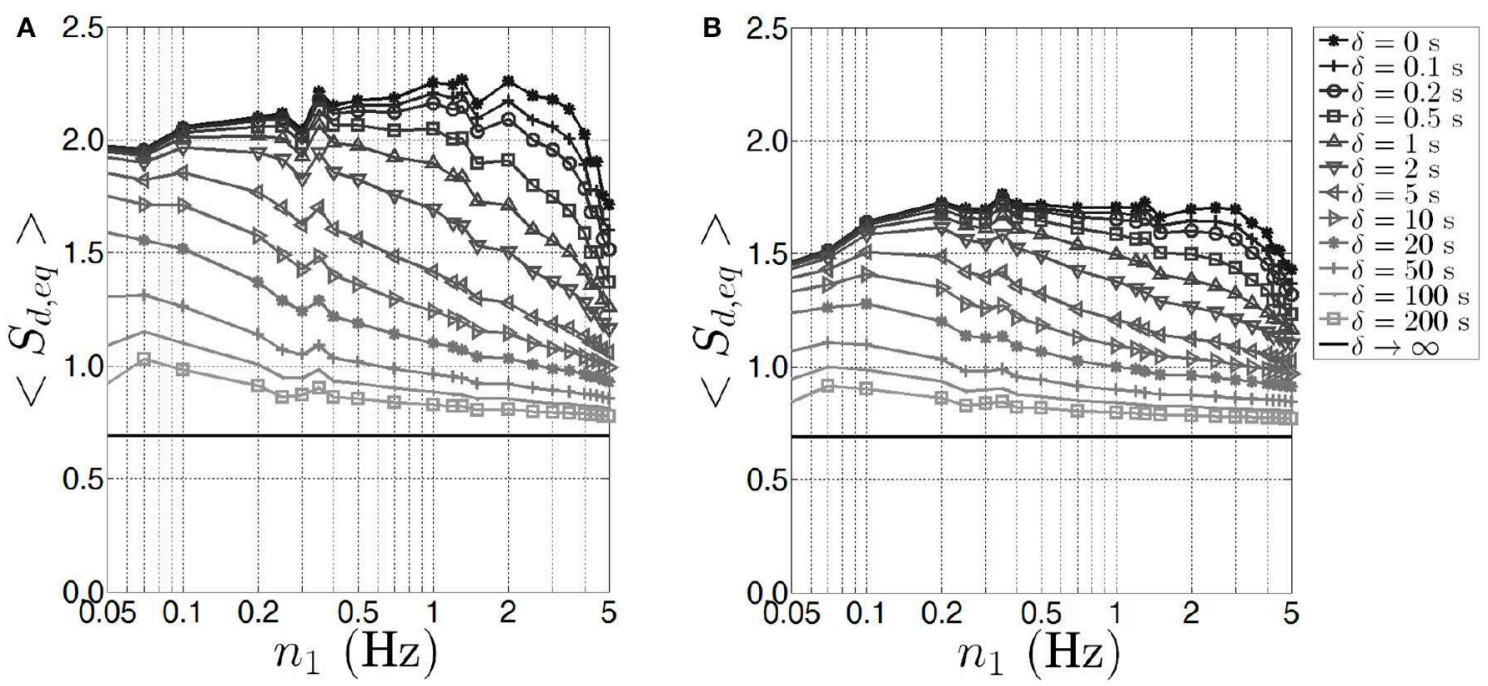

FIGURE 11 | Equivalent response spectrum: (A) $x=0.002 ;(B) x=0.01$. Reproduced from Solari and De Gaetano (2018) with permission from Elsevier

extreme wind speed distribution (Zhang et al., 2018b) confirmed that, as in many other parts of the planet, the strongest wind events in the High Tyrrhenian area are due to thunderstorms.

The second objective regards thunderstorm loading and response of structures. Two towers have been equipped with anemometers, accelerometers, and strain-gauges to gather simultaneous data of the outflow velocity and structural response. Research is in progress to develop three complementary methods for evaluating the wind loading of structures: response spectrum technique (Figure 11) (Solari et al., 2015b; Solari, 2016), time-domain analysis (Solari et al., 2017), and non-stationary random dynamics by the evolutionary power spectral density (EPSD) method. The joint calibration and evolution of the first two methods led to substantial agreement (Solari and De Gaetano, 2018), confirming the efficacy of the thunderstorm response spectrum technique in structural design. A novel piece of research has been carried out on directionality effects on wind loading (Brusco et al., 2019). Research is also in progress to replace the classic wind loading by two loading conditions, one for cyclones and the other for thunderstorms, creating a novel set of partial and combination factors for thunderstorm outflows (Solari, 2014). In the next project stages wind loading will be evaluated by the classical method and the new format for an extensive archive of structure test-cases in order to evaluate additional costs and savings due to the new methods.

Summarizing the above statements, the THUNDERR project aims to fill the main gaps pointed out in the state-of-the-art sections by building robust methods based on measurements. Under this point of view, it provides a unique opportunity to overcome shortcomings, turn pages, and open new routes for wind and structural engineering, enhancing the safety and sustainability of built environment.

\section{CONCLUSIONS AND PROSPECTS}

The study of thunderstorm downbursts is a key issue of research in wind engineering and atmospheric science. Despite the effort carried out worldwide, however, the modeling of downbursts and their impact on the built environment is still dominated 
by many uncertainties, by the lack of a shared model of this phenomenon and its loading of structures, and by the need for a framework in which wind loading due to synoptic events and thunderstorm outflows are encapsulated. This aspect is a major shortcoming in wind and structural engineering because wind is the most destructive natural hazard and in many parts of the world thunderstorm outflows produce design wind speeds.

The ERC THUNDERR project represents a unique opportunity to turn the page, fill the existing gaps, and shed new light on several issues that are waiting answers and solutions. The path to take, however, is still very long and difficult.

The author believes that the fundamental prospect is to pursue an interdisciplinary vision, such as to break down the many borders that still contribute to creating serious limitations to the development of knowledge. Firstly, it is desirable that wind engineering and atmospheric science find the stimuli and means to create a shared view. It is also essential that full-scale measurements, theoretical models, laboratory tests, computational simulations, and physical interpretations contribute, in an integrated way, to building a wider culture.

Within this scenario, the author considers it a priority to acquire field information on the touch-down position and diameter of downdrafts, their translational speed and direction, the relations between the downburst wind field and the background flow, the time evolution of the profile of the wind speed, the duration of the ramp-up phase related to the passage of the gust front, and its link with the gust peak.

From this vision must derive the awareness that the measurement of the wind as it is performed now by most weather stations is implicitly and inextricably linked to the phenomena at a synoptic scale. This deprives such measurements of the information necessary to recognize the occurrence of events on a local scale, such as downbursts, and does not provide the data required to depict their space-time properties. Recognizing the

\section{REFERENCES}

Abd-Elaal, E. S., Mills, J. E., and Ma, X. (2013a). An analytical model for simulating steady state flows of downburst. J. Wind Eng. Indus. Aerodyn. 115, 53-64. doi: 10.1016/j.jweia.2013.01.005

Abd-Elaal, E. S., Mills, J. E., and Ma, X. (2013b). A coupled parametricCFD study for determining ages of downbursts through investigation of different field parameters. J. Wind Eng. Indus. Aerodyn. 123, 30-42. doi: 10.1016/j.jweia.2013.09.010

Aboshosha, H., Bitsuamlak, G., and El Damatty, A. (2015). Turbulence characterization of downbursts using LES. J. Wind Eng. Indus. Aerodyn. 136, 44-61. doi: 10.1016/j.jweia.2014.10.020

Aboshosha, H., and El Damatty, A. (2015). Engineering method for estimating the reactions of transmission line conductors under downburst winds. Eng. Struct. 99, 272-284. doi: 10.1016/j.engstruct.2015.04.010

Aboshosha, H., Elawady, A., El Ansary, A., and El Damatty, A. (2016). Review on dynamic and quasi-static buffeting response of transmission lines under synoptic and non-synoptic winds. Eng. Struct. 112, 23-46. doi: 10.1016/j.engstruct.2016.01.003

Aboshosha, H., Mara, T., and Case, P. (2017). "New framework for estimating thunderstorm design speed," in 13th Americas Conference on Wind Engineering (Gainesville, FL).

Aboutabikh, M., Ghazal, T., Chen, J., Elgamal, S., and Aboshosha, H. (2019). Designing a blade-system to generate downburst outflows at severity of this limitation may favor a generational change in the format of the data and may allow for a renewed study of this phenomenon.

Meanwhile, the need to transfer this new information into the modeling of downburst wind loading of structures, a theme now dealt with on mainly theoretical basis, without the background of the physical knowledge of the exciting phenomenon, has become more evident. The author believes that structural engineering should first acquire a renewed viewpoint on single buildings, then enlarge it to the built environment, and finally approach a joint vision and a renewed knowledge of safety and sustainability that cannot be delayed any further.

\section{AUTHOR CONTRIBUTIONS}

The author confirms being the sole contributor of this work and has approved it for publication.

\section{FUNDING}

This research was funded by the European Research Council (ERC) under the European Union's Horizon 2020 research and innovation program (grant agreement No. 741273) for the project THUNDERR-Detection, simulation, modeling, and loading of thunderstorm outflows to design wind-safer and cost-efficient structures-supported by an Advanced Grant 2016.

\section{ACKNOWLEDGMENTS}

The author is grateful to Springer for authorizing him to use the lecture delivered at the 15th International Conference of the Italian Association for Wind Engineering as the starting point for compiling this paper. boundary layer wind tunnel. J. Wind Eng. Indus. Aerodyn. 186, 169-191. doi: 10.1016/j.jweia.2019.01.005

Alahyari, A., and Longmire, E. K. (1995). Dynamics of experimentally simulated microburst. AIAA J. 33, 2128-2136. doi: 10.2514/3.12957

Allen, J. T., Karoly, D. J., and Walsh, K. J. (2014). Future Australian severe thunderstorm environments. Part II: the influence of a strongly warming climate on convective environments. J. Clim. 27, 3848-3868. doi: 10.1175/JCLI-D-13-00426.1

American Society of Civil Engineers (1961). Wind forces on structures. Trans. ASCE 126(II), 1124-1198.

Anderson, J. R., Orf, L. G., and Straka, J. M. (1992). A 3-D model system for simulating thunderstorms microburst outflows. Meteorol. Atmos. Phys. 49, 123-131. doi: 10.1007/BF01025404

Asano, K., Iida, Y., and Uematsu, Y. (2019). A laboratory study of wind loads on a low-rise building in a downburst using a moving pulsed jet simulator and their comparison with other types of simulators. J. Wind Eng. Indus. Aerodyn. 184, 313-320. doi: 10.1016/j.jweia.2018.11.034

Bakke, P. (1957). An experimental investigation of a wall jet. J. Fluid Mech. 125, 467-472. doi: 10.1017/S0022112057000270

Barratt, P., and Browne, I. C. (1953). A new method for measuring vertical air currents. Q. J. R. Meteorol. Soc. 79, 550-560. doi: 10.1002/qj.49707934218

Blocken, B. (2014). 50 years of Computational Wind Engineering: past, present and future. J. Wind Eng. Indus. Aerodyn. 129, 69-102. doi: 10.1016/j.jweia.2014.03.008 
Bohun, R. (1671). A Discourse Concerning the Origins and Properties of Wind. Oxford: Hall.

Brooks, C. F. (1922). The local or heat thunderstorm. Mon. Weather Rev. 50, 281-287. doi: 10.1175/1520-0493(1922)50<281:TLOHT>2.0.CO;2

Brooks, H. E. (2013). Severe thunderstorms and climate change. Atmos. Res. 123 , 129-138. doi: 10.1016/j.atmosres.2012.04.002

Brooks, H. E., Lee, J. W., and Craven, J. P. (2003). The spatial distribution of severe thunderstorm and tornado environments from global reanalysis data. Atmos. Res. 67-68, 73-94. doi: 10.1016/S0169-8095(03)00045-0

Brown, R. A., and Lewis, J. M. (2005). Path to NEXRAD: Doppler radar development at the National Severe Storms Laboratory. Bull. Am. Meteorol. Soc. 86, 1459-1470. doi: 10.1175/BAMS-86-10-1459

Brusco, S., Lerzo, V., and Solari, G. (2019). Directional response of structures to thunderstorm outflows. Meccanica 54, 1281-1306. doi: 10.1007/s11012-019-00986-5

Burlando, M., De Cio, A., Pizzo, M., and Solari, G. (2017a). "Analysis of wind vertical profiles of thunderstorm events in the Mediterranean," in 9th AsiaPacific Conference on Wind Engineering (Auckland).

Burlando, M., Romanic, D., Solari, G., Hangan, H., and Zhang, S. (2017b). Field data analysis and weather scenario of a downburst event in Livorno, Italy on 1 October 2012. Mon. Weather Rev. 145, 3507-3527. doi: 10.1175/MWR-D-17-0018.1

Burlando, M., Zhang, S., and Solari, G. (2018). Monitoring, cataloguing and weather scenarios of thunderstorm-induced intense wind events. Nat. Hazard Earth Syst. 18, 2309-2330. doi: 10.5194/nhess-18-2309-2018

Butler, K., Cao, S., Kareem, A., Tamura, Y., and Ozono, S. (2010). Surface pressure and wind load characteristics on prisms immersed in a simulated transient gust front flow field. J. Wind Eng. Indus. Aerodyn. 98, 299-316. doi: 10.1016/j.jweia.2009.11.003

Butler, K., and Kareem, A. (2007). "Physical and numerical modeling of downburst generated gust fronts," in 12th International Conference on Wind Engineering (Cairns, QLD).

Byers, H. R., and Braham, R. R. (1949). The Thunderstorm: Final Report of the Thunderstorm Project. Washington, DC: U.S. Government Printing Office.

Calotescu, I. (2018). "Overview of recent wind-induced damage in Romania based on mass-media reports," in International Workshop on Wind-Related Disasters and Mitigation (Sendai).

Cao, S., Nishi, A., and Kikugawa, H. (2002). Reproduction of wind velocity history in a multiple fan wind tunnel. J. Wind Eng. Indus. Aerodyn. 90, 1719-1729. doi: 10.1016/S0167-6105(02)00282-9

Caracoglia, L. (2018). Unified stochastic dynamic and damage cost model for the structural analysis of tall buildings in thunderstorm-like winds. ASCE-ASME J. Risk Uncertain. Eng. Syst. 4:04018043. doi: 10.1061/AJRUA6.0000999

Cermak, J. E. (1975). Applications of fluid mechanics to wind engineering - A Freeman Scholar Lecture. J. Fluid Eng.Trans. ASME 97, 9-38. doi: $10.1115 / 1.3447225$

Charba, J. (1974). Application of gravity current model to analysis of squallline gust front. Mon Weather Rev. 102, 140-156. doi: 10.1175/15200493(1974)102<0140:AOGCMT>2.0.CO;2

Chay, M., and Albermani, F. (2005). "Dynamic response of a SDOF system subjected to simulated downburst winds," in 6th Asia-Pacific Conference on Wind Engineering (Seoul).

Chay, M. T., Albermani, F., and Wilson, B. (2006). Numerical and analytical simulation of downburst wind loads. Eng. Struct. 28, 240-254. doi: 10.1016/j.engstruct.2005.07.007

Chay, M. T., and Letchford, C. W. (2002). Pressure distributions on a cube in a simulated thunderstorm downburst. Part A: stationary downburst observations. J. Wind Eng. Indus. Aerodyn. 90, 711-732. doi: 10.1016/S0167-6105(02)00158-7

Chay, M. T., Wilson, R., and Albermani, F. (2008). Gust occurrence in simulated non-stationary winds. J. Wind Eng. Indus. Aerodyn. 96, 2161-2172. doi: 10.1016/j.jweia.2008.02.059

Chen, L., and Letchford, C. W. (2004a). A deterministic-stochastic hybrid model of downbursts and its impact on a cantilevered structure. Eng. Struct. 26, 619-629. doi: 10.1016/j.engstruct.2003.12.009

Chen, L., and Letchford, C. W. (2004b). Parametric study on the alongwind response of the CAARC building to downbursts in the time domain. J. Wind Eng. Indus. Aerodyn. 92, 703-724. doi: 10.1016/j.jweia.2004.03.001
Chen, L., and Letchford, C. W. (2005). Proper orthogonal decomposition of two vertical profiles of full-scale non-stationary correlated downburst wind speeds. J. Wind Eng. Indus. Aerodyn. 93, 187-266. doi: 10.1016/j.jweia.2004.11.004

Chen, L., and Letchford, C. W. (2006). Multi-scale correlation analyses of two lateral profiles of full-scale downburst wind speeds. J. Wind Eng. Indus. Aerodyn. 94, 675-696. doi: 10.1016/j.jweia.2006.01.021

Chen, L., and Letchford, C. W. (2007). Numerical simulation of extreme winds from thunderstorm downbursts. J. Wind Eng. Indus. Aerodyn. 95, 977-990. doi: 10.1016/j.jweia.2007.01.021

Chen, X. (2008). Analysis of alongwind tall building response to transient nonstationary winds. J. Struct. Eng. ASCE 134, 782-791. doi: 10.1061/(ASCE)0733-9445(2008)134:5(782)

Chen, X. (2015). Analysis of multimode coupled buffeting response of long-span bridges to non-stationary winds with force parameters from stationary wind. J. Struct. Eng. ASCE 141:04014131. doi: 10.1061/(ASCE)ST.1943-541X.0001078

Choi, E. C. C. (1999). Extreme wind characteristics over Singapore - An area in the equatorial belt. J. Wind Eng. Indus. Aerodyn. 83, 61-69. doi: 10.1016/S0167-6105(99)00061-6

Choi, E. C. C. (2000). Wind characteristics of tropical thunderstorms. J. Wind Eng. Indus. Aerodyn. 84, 215-226. doi: 10.1016/S0167-6105(99)00054-9

Choi, E. C. C. (2004). Field measurement and experimental study of wind speed during thunderstorms. J. Wind Eng. Indus. Aerodyn. 92, 275-290. doi: 10.1016/j.jweia.2003.12.001

Choi, E. C. C., and Hidayat, F. A. (2002a). Dynamic response of structures to thunderstorm winds. Prog. Struct. Eng. Mater. 4, 408-416. doi: 10.1002/pse.132

Choi, E. C. C., and Hidayat, F. A. (2002b). Gust factors for thunderstorm and non-thunderstorm winds. J. Wind Eng. Indus. Aerodyn. 90, 1683-1696. doi: 10.1016/S0167-6105(02)00279-9

Choi, E. C. C., and Tanurdjaja, A. (2002). Extreme wind studies in Singapore. An area with mixed weather system. J. Wind Eng. Indus. Aerodyn. 90, 1611-1630. doi: 10.1016/S0167-6105(02)00274-X

Clark, T. L. (1979). Numerical simulations with a three-dimensional cloud model: lateral boundary condition experiments and multicellular severe storm simulations. J. Atmos. Sci. 36, 2191-2215. doi: 10.1175/15200469(1979)036<2191:NSWATD >2.0.CO;2

Cook, N. J., Harris, R. I., and Whiting, R. (2003). Extreme wind speeds in mixed climates revisited. J. Wind Eng. Indus. Aerodyn. 91, 403-422. doi: 10.1016/S0167-6105(02)00397-5

Cooper, D., Jackson, D. C., Launder, B. E., and Liao, G. X. (1993). Impinging jet studies for turbulence model assessment - I. flow fields experiments. Int. J. Heat Mass Trans. 36, 2675-2684. doi: 10.1016/S0017-9310(05)80204-2

Cotton, W. R., and Tripoli, G. J. (1978). Cumulus convection in shear flow threedimensional numerical experiments. J. Atmos. Sci. 35, 1503-1521. doi: 10.1175/ 1520-0469(1978)035<1503:CCISFD > 2.0.CO;2

Darwish, M. D., and El Damatty, A. A. (2011). Behavior of self-supported transmission line towers under stationary downburst loading. Wind Struct. 14, 481-498. doi: 10.12989/was.2011.14.5.481

Darwish, M. M., El Damatty, A., and Hangan, H. (2010). Dynamic characteristics of transmission line conductors and bahaviour under turbulent downburst loading. Wind Struct. 13, 327-346. doi: 10.12989/was.2010.13.4.327

Davenport, A. G. (1961). The application of statistical concepts to the wind loading of structures. Proc. Inst. Civil Eng. 19, 449-472. doi: 10.1680/iicep.1961.11304

Davenport, A. G. (1968). "The dependence of wind loads on meteorological parameters," in Proceedings International Research Seminar "Wind Effects on Buildings and Structures" (Ottawa, ON).

Davis, W. M. (1894). Elementary Meteorology. Boston, MA, Ginn.

De Coning, E., Koenig, M., and Olivier, J. (2011). The combined instability index: a new very-short range convection forecasting technique for southern Africa. Meteorol. Appl. 18, 421-439. doi: 10.1002/met.234

De Gaetano, P., Repetto, M. P., Repetto, T., and Solari, G. (2014). Separation and classification of extreme wind events from anemometric records. J. Wind Eng. Indus. Aerodyn. 126, 132-143. doi: 10.1016/j.jweia.2014. 01.006

Del Genio, A., Yao, M. S., and Jonas, J. (2007). Will moist convection be stronger in a warmer climate? Geophys. Res. Lett. 34:16703. doi: 10.1029/2007GL030525

Didden, N., and Ho, C. M. (1985). Unsteady separation in a boundary layer produced by an impinging jet. J. Fluid Mech. 160, 235-256. doi: $10.1017 /$ S0022112085003469 
Diffenbaugh, N. S., Scherer, M., and Trapp, R. J. (2013). Robust increases in severe thunderstorm environments in response to greenhouse forcing. Proc. Natl. Acad. Sci. U.S.A. 110, 361-366. doi: 10.1073/pnas.1307758110

Donaldson, C. D., and Snedeker, R. S. (1971). A study of free jet impingement. Part 1. mean properties of free and impinging jet. J. Fluid Mech. 45, 235-256. doi: 10.1017/S0022112071000053

Droegemeier, K. K., and Wjlhelmson, R. B. (1987). Numerical simulation of thunderstorm outflow dynamics. Part 1: outflow sensitivity and turbulence dynamics. J. Atmos. Sci. 44, 1180-1210. doi: 10.1175/15200469(1987)044<1180:NSOTOD>2.0.CO;2

Duranona, V. (2015). "The significance of non-synoptic winds in extreme wind climate of Uruguay," in 14th International Conference on Wind Engineering (Porto Alegre).

Duranona, V., Sterling, M., and Baker, C. J. (2006). An analysis of extreme non-synoptic winds. J. Wind Eng. Indus. Aerodyn. 95, 1007-1027. doi: 10.1016/j.jweia.2007.01.014

Eiffel, A. G. (1909). The Resistance of the Air and Aviation: Experiments Conducted at the Champ-de-Mars Laboratory. Paris: Dunot \& Pinat.

El Damatty, A., and Elawady, A. (2018). Critical load cases for lattice transmission line structures subjected to downbursts: economic implications for design of transmission lines. Eng. Struct. 159, 213-226. doi: 10.1016/j.engstruct.2017.12.043

Elawadi, A., Aboshosha, H., El Damatty, A., Bitsuamlak, G., Hangan, H., and Elatar, A. (2017). Aero-elastic testing of multi-spanned transmission line subjected to downbursts. J. Wind Eng. Indus. Aerodyn. 169, 194-216. doi: 10.1016/j.jweia.2017.07.010

Elawady, A., Aboshosha, H., and El Damatty, A. (2018). Aero-elastic response of transmission line system subjected to downburst wind: validation of numerical model using experimental data. Wind Struct. 27, 71-88. doi: 10.12989/was.2018.27.2.071

Espy, J. P. (1841). The Philosophy of Storms. Boston, MA: Little and Brown. doi: $10.5479 /$ sil.1109113.39088016470767

Ferrel, W. (1889). A Popular Treatise on the Winds: Comprising the General Motions of the Atmosphere, Monsoons, Cyclones, Tornadoes, Waterspouts, Hailstorms, etc. New York, NY: Wiley.

Fidler, T. C. (1887). A Practical Treatise on Bridge Construction. London: Charles Griffin.

Finley, J. P. (1882). "Character of six hundred tornadoes," in Prof. Papers of the Signa1 Service VII (Washington: Washington Office of the Chief Signal Officer).

Fleming, R. (1930). Wind Stresses in Buildings. New York, NY: Wiley.

Fujita, T. T. (1981). Tornadoes and downbursts in the context of generalized planetary scales. J. Atmos. Sci. 38, 1511-1534. doi: 10.1175/15200469(1981)038<1511:TADITC >2.0.CO;2

Fujita, T. T. (1985). Downburst: Microburst and Macroburst. Chicago, IL: University of Chicago Press.

Fujita, T. T. (1990). Downburst: meteorological features and wind field characteristics. J. Wind Eng. Indus. Aerodyn. 36, 75-86. doi: 10.1016/0167-6105(90)90294-M

Fujita, T. T., and Wakimoto, R. M. (1981). Five scales of airflow associated with a series of downbursts on 16 July 1980. Mon. Weather Rev. 109, 1438-1456. doi: 10.1175/1520-0493(1981)109<1438:FSOAAW >2.0.CO;2

Galway, J. G. (1956). The Lifted Index as a predictor of latent instability. Bull. Am. Meteorol. Soc. 37, 528-529. doi: 10.1175/1520-0477-37.10.528

Geerts, B. (2001). Estimating downburst-related maximum surface wind speeds by means of proximity soundings in New South Wales, Australia. Weather Forecast. 16, 261-269. doi: 10.1175/1520-0434(2001)016<0261:EDRMSW>2.0. $\mathrm{CO} ; 2$

Georgiou, P. N., Davenport, A. G., and Vickery, B. J. (1983). Design wind speeds in regions dominated by tropical cyclones. J. Wind Eng. Indus. Aerodyn. 13, 139-152. doi: 10.1016/0167-6105(83)90136-8

Glauert, M. B. (1956). The wall jet. J. Fluid Mech. 1, 625-643. doi: 10.1017/S002211205600041X

Goff, R. G. (1976). Vertical structure of thunderstorm outflows. Mon. Weather Rev. 104, 1429-1440. doi: 10.1175/1520-0493(1976)104<1429:VSOTO >2.0.CO;2

Gomes, L., and Vickery, B. J. (1976). On thunderstorm wind gusts in Australia. Civil Eng. Trans. Inst. Eng. 18, 33-39.

Gomes, L., and Vickery, B. J. (1977/1978). Extreme wind speeds in mixed climates. J. Indus. Aerodyn. 2, 331-344. doi: 10.1016/0167-6105(78)90018-1
Gunter, W. S., and Schroeder, J. L. (2015). High-resolution full-scale measurements of thunderstorm outflow winds. J. Wind Eng. Indus. Aerodyn. 138, 13-26. doi: 10.1016/j.jweia.2014.12.005

Haines, M., and Taylor, I. (2018). Numerical investigation of the flow field around low rise buildings due to a downburst event using large eddy simulation. J. Wind Eng. Indus. Aerodyn. 172, 12-30. doi: 10.1016/j.jweia.2017.10.028

Haklander, A. J., and Van Delden, A. (2003). Thunderstorm predictors and their forecast skill for the Netherlands. Atmos. Res. 67-68, 273-299. doi: 10.1016/S0169-8095(03)00056-5

Hangan, H., Refan, M., Jubayer, C., Romanic, D., Parvu, D., Lo Tufo, J., et al. (2017). Novel techniques in wind engineering. J. Wind Eng. Indus. Aerodyn. 171, 12-33. doi: 10.1016/j.jweia.2017.09.010

Hirth, B. D., Schroeder, J. L., and Weiss, C. C. (2008). Surface analysis of the rearflank downdraft outflow in two tornadic supercells. Mon. Weather Rev. 136, 2344-2363. doi: 10.1175/2007MWR2285.1

Hjelmfelt, M. R. (1988). Structure and life cycle of microburst outflows observed in Colorado. J. Appl. Meteorol. 27, 900-927. doi: 10.1175/15200450(1988)027<0900:SALCOM>2.0.CO;2

Hjelmfelt, M. R., Roberts, R. D., Orville, H. D., Chen, J. P., and Kopp, F. J. (1989). Observational and numerical study of a microburst lineproducing storm. J. Atmos. Sci. 46, 2713-2744. doi: 10.1175/15200469(1989)046<2731:OANSOA>2.0.CO;2

Holmes, J., Forristall, G., and McConochie, J. (2005). "Dynamic response of structures to thunderstorm winds," in 10th American Conference on Wind Engineering (Baton Rouge, LA).

Holmes, J. D. (1999). "Modelling of extreme thunderstorm winds for wind loading of structures and risk assessment," in Wind Engineering Into the 21st Century, eds A. Larsen and G. Larose (Copenhagen: Balkema).

Holmes, J. D., Hangan, H. M., Schroeder, J. L., Letchford, C. W., and Orwig, K. D. (2008). A forensic study of the Lubbock-Reese downdraft of 2002. Wind Struct. 11, 19-39. doi: 10.12989/was.2008.11.2.137

Holmes, J. D., and Oliver, S. E. (2000). An empirical model of a downburst. Eng. Struct. 22, 1167-1172. doi: 10.1016/S0141-0296(99)00058-9

Housner, G. W., Martel, R. R., and Alford, J. L. (1953). Spectrum analysis of strong-motion earthquakes. Bull. Seism. Soc. Am. 43, 97-119.

Huang, G. (2014). An efficient simulation approach for multivariate nonstationary process: hybrid of wavelet and spectral representation method. Probabil. Eng. Mech. 37, 74-83. doi: 10.1016/j.probengmech.2014.06.001

Huang, G., and Chen, X. (2009). Wavelets-based estimation of multivariate evolutionary spectra and its application to nonstationary downburst winds. Eng. Struct. 31, 976-989. doi: 10.1016/j.engstruct.2008.12.010

Huang, G., Chen, X., Liao, H., and Li, M. (2013). Predicting of tall building response to non-stationary winds using multiple wind speed samples. Wind Struct. 17, 227-244. doi: 10.12989/was.2013.17.2.227

Huang, G., Jiang, Y., Peng, L., Solari, G., Liao, H., and Li, M. (2019). Characteristics of intense wind in mountain area based on field measurement. J. Wind Eng. Indus. Aerodyn. 190, 166-182. doi: 10.1016/j.jweia.2019.04.020

Huang, G., Liu, W., Zhou, Q., Yan, Z., and Zuo, D. (2018). Numerical study for downburst wind and its load on high-rise buildings. Wind Struct. 27, 89-100. doi: 10.12989/was.2018.27.2.089

Huang, G., Peng, L., Su, Y., Liao, H., and Li, M. (2015a). A wireless high-frequency anemometer instrumentation system for field measurements. Wind Struct. 20, 739-749. doi: 10.12989/was.2015.20.6.739

Huang, G., Zheng, H., Xu, Y. L., and Li, Y. (2015b). Spectrum models for non-stationary extreme winds. J. Struct. Eng. ASCE 141:04015010. doi: 10.1061/(ASCE)ST.1943-541X.0001257

Huntrieser, H., Schiesser, H. H., Schmid, W., and Waldvogel, A. (1997). Comparison of traditional and newly developed thunderstorm indices for Switzerland. Weather Forecast. 12, 108-125. doi: 10.1175/15200434(1997)012<0108:COTAND>2.0.CO;2

Iida, Y., and Uematsu, Y. (2019). Numerical study of wind loads on buildings induced by downbursts. J. Wind Eng. Indus. Aerodyn. 191, 103-116. doi: 10.1016/j.jweia.2019.05.018

Ivan, M. (1986). A ring-vortex downburst model for flight simulations. J. Aircraft 23, 232-236. doi: $10.2514 / 3.45294$

Iwashita, H., and Kobayashi, F. (2019). Transition of meteorological variables while downburst occurrence by high density ground surface observation network. J. Wind Eng. Indus. Aerodyn. 184, 153-161. doi: 10.1016/j.jweia.2018.10.007 
Jacovides, C. P., and Yonetani, T. (1990). An evaluation of stability indices for thunderstorm prediction in greater cyprus. Weather Forecast. 560, 559-569. doi: 10.1175/1520-0434(1990)005<0559:AEOSIF>2.0.CO;2

Jarvi, L., Punkka, A. J., Schultz, D. M., Petaja, T., Hohti, H., Rinne, J., et al. (2007). Micrometeorological observations of a microburst in southern Finland. Bound. Lay Meteorol. 125, 343-359. doi: 10.1007/s10546-007-9204-7

Jesson, M., and Sterling, M. (2018). A simple vortex model of a thunderstorm downburst - a parametric evaluation. J. Wind Eng. Indus. Aerodyn. 174, 1-9. doi: 10.1016/j.jweia.2017.12.001

Jesson, M., Sterling, M., Letchford, C., and Baker, C. (2015). Aerodynamic forces on the roofs of low-, mid- and high-rise buildings subject to transient winds. J. Wind Eng. Indus. Aerodyn. 143, 42-49. doi: 10.1016/j.jweia.2015.04.020

Jubayer, C., Elatar, A., and Hangan, H. (2016). "Pressure distributions on a low-rise building in a laboratory simulated downburst," in 8th International Colloquium on Bluff-Body Aerodynamics and Applications (Boston, MA).

Junayed, C., Jubayer, C., Parvu, D., Romanic, D., and Hangan, H. (2019). Flow field dynamics of large-scale experimentally produced downburst flows. J. Wind Eng. Indus. Aerodyn. 188, 61-79. doi: 10.1016/j.jweia.2019. 02.008

Kareem, A., Guo, Y., and Hu, L. (2016). “Time-frequency modeling framework for non-stationary aerodynamic load effects," in 8th International Colloquium on Bluff-Body Aerodynamics and Applications (Boston, MA).

Karman, T. (1948). "L'aerodynamique dans l'art de ingénieur," in Mémoires de la Société des Ingenieurs Civils de France (Paris), 155-178.

Kasperski, M. (2002). A new wind zone map of Germany. J. Wind Eng. Indus. Aerodyn. 90, 1271-1287. doi: 10.1016/S0167-6105(02)00257-X

Katsura, J. (1997). Some conceptions for the flow pattern formation around bluff bodies in natural winds. J. Wind Eng. Indus. Aerodyn. 66, 1-15. doi: 10.1016/S0167-6105(97)00010-X

Kim, J., and Hangan, H. (2007). Numerical simulations of impinging jets with application to downbursts. J. Wind Eng. Indus. Aerodyn. 95, 279-298. doi: $10.1016 /$ j.jweia.2006.07.002

Klemp, J. B., and Wilhelmson, R. B. (1978). The simulation of three-dimensional convective storm dynamics. J. Atmos. Sci. 35, 1070-1096. doi: 10.1175/15200469(1978)035<1070:TSOTDC>2.0.CO;2

Knupp, K. R. (1989). Numerical simulation of low-level downdraft initiation within precipitating cumulonimbi: some preliminary results. Mon. Weather Rev. 117, 1517-1529.2.0. doi: 10.1175/1520-0493(1989)117<1517:NSOLLD $>2$. $0 . \mathrm{CO} ; 2$

Kunz, M., Sander, J., and Kottmeier, Ch. (2009). Recent trends of thunderstorm and hailstorm frequency and their relation to atmospheric characteristics in southwest Germany. Int. J. Climatol. 29, 2283-2297. doi: 10.1002/joc.1865

Kwon, D. K., and Kareem, A. (2009). Gust-front factor: new framework for wind load effects on structures. J. Struct. Eng. ASCE 135, 717-732. doi: 10.1061/(ASCE)0733-9445(2009)135:6(717)

Kwon, D. K., and Kareem, A. (2019). Towards codification of thunderstorm/downburst using gust front factor: model-based and data-driven perspectives. Eng. Struct. 199:109608. doi: 10.1016/j.engstruct.2019.109608

Landreth, C. C., and Adrian, R. J. (1990). Impingement of a low Reynolds number turbulent circular jet onto a flat plate at normal incidence. Exp. Fluids. 9, 74-84. doi: 10.1007/BF00575338

Launder, B. E., and Rodi, W. (1983). The turbulent wall jet measurements and modeling. Annu. Rev. Fluid Mech. 15, 429-459. doi: 10.1146/annurev.fl.15.010183.002241

Le, T. H., and Caracoglia, L. (2015a). Reduced-order wavelet-Galerkin solution for the coupled, nonlinear stochastic response of slender buildings in transient winds. J. Sound Vib. 344, 179-208. doi: 10.1016/j.jsv.2015.01.007

Le, T. H., and Caracoglia, L. (2015b). Wavelet-Galerkin analysis to study the coupled dynamic response of a tall building against transient wind loads. Eng. Struct. 100, 763-788. doi: 10.1016/j.engstruct.2015. 03.060

Le, T. H., and Caracoglia, L. (2016). Modeling vortex-shedding effects for the stochastic response of tall buildings in non-synoptic winds. J. Fluid Struct. 61, 461-491. doi: 10.1016/j.jfluidstructs.2015.12.006

Le, T. H., and Caracoglia, L. (2017). Computer-based model for the transient dynamics of a tall building during digitally simulated Andrews AFB thunderstorm. Comput. Struct. 193, 44-72. doi: 10.1016/j.compstruc.2017.07.019
Le, V., and Caracoglia, L. (2018). Computationally efficient stochastic approach for the fragility analysis of vertical structures subjected to thunderstorm downburst winds. Eng. Struct. 165, 152-169. doi: 10.1016/j.engstruct.2018.03.007

Le, V., and Caracoglia, L. (2019). Generation and characterization of a nonstationary flow field in a small-scale wind tunnel using a multi-blade flow device. J. Wind Eng. Indus. Aerodyn. 186, 1-16. doi: 10.1016/j.jweia.2018.12.017

Letchford, C. W., and Chay, M. T. (2002). Pressure distributions on a cube in a simulated thunderstorm downburst. Part B: moving downburst observations. J. Wind Eng. Indus. Aerodyn. 90, 733-753. doi: 10.1016/S0167-6105(02)00163-0

Letchford, C. W., and Lombardo, F. T. (2015). "Is codification of non-synoptic wind load possible?" in 14th International Conference on Wind Engineering (Porto Alegre).

Letchford, C. W., Mans, C., and Chay, M. T. (2002). Thunderstorms - their importance in wind engineering (a case for the next generation wind tunnel). J. Wind Eng. Indus. Aerodyn. 90, 1415-1433. doi: 10.1016/S0167-6105(02)00262-3

Li, C., Li, Q. S., Xiao, Y. Q., and Ou, J. P. (2012). A revised empirical model and CFD simulations for 3D axisymmetric steady-state flows of downbursts and impinging jets. J. Wind Eng. Indus. Aerodyn. 102, 48-60. doi: 10.1016/j.jweia.2011.12.004

Li, C. Q. (2000). A stochastic model of severe thunderstorms for transmission line design. Probabil. Eng. Mech. 15, 359-364. doi: 10.1016/S0266-8920(99)00037-5

Lilly, D. K. (1979). The dynamical structure and evolution of thunderstorms and squall lines. Annu. Rev. Earth Planet Sci. 7, 117-161. doi: 10.1146/annurev.ea.07.050179.001001

Lin, W. E., Mara, T. G., and Savory, E. (2015). "Wind velocity profiles from a pulsed wall jet over ground roughness," in 14th International Conference on Wind Engineering (Porto Alegre).

Lin, W. E., Orf, L. G., Savory, E., and Novacco, C. (2007). Proposed large-scale modelling of the transient features of a downburst outflow. Wind Struct. 10, 315-346. doi: 10.12989/was.2007.10.4.315

Lin, W. E., and Savory, E. (2006). Large-scale quasi-steady modeling of a downburst outflow using a slot jet. Wind Struct. 9, 419-440. doi: 10.12989/was.2006.9.6.419

Liu, J. Y., and Orville, H. D. (1969). Numerical modeling of precipitation and cloud shadow effects on mountain-induced cumuli. J. Atmos. Sci. 26, 1283-1298. doi: 10.1175/1520-0469(1969)026<1283:NMOPAC>2.0.CO;2

Lombardo, F. T., Main, J. A., and Simiu, E. (2009). Automated extraction and classification of thunderstorm and non-thunderstorm wind data for extreme-value analysis. J. Wind Eng. Indus. Aerodyn. 97, 120-131. doi: 10.1016/j.jweia.2009.03.001

Lombardo, F. T., Mason, M. S., and De Alba, A. Z. (2018). Investigation of a downburst loading event on a full-scale low-rise building. J. Wind Eng. Indus. Aerodyn. 182, 277-285. doi: 10.1016/j.jweia.2018.09.020

Lombardo, F. T., Smith, D. A., Schroeder, J. L., and Mehta, K. C. (2014). Thunderstorm characteristics of importance to wind engineering. J. Wind Eng. Indus. Aerodyn. 125, 121-132. doi: 10.1016/j.jweia.2013.12.004

Lombardo, F. T., and Zickar, A. S. (2019). Characteristics of measured thunderstorm near-surface wind gusts in the United States. J. Wind Eng. Indus. Aerodyn. 193, 103961. doi: 10.1016/j.jweia.2019.103961

Lompar, M., Curic, M., and Romanic, D. (2018). Implementation of a gust front head collapse scheme in the WRF numerical model. Atmos. Res. 203, 231-245. doi: 10.1016/j.atmosres.2017.12.018

Loredo-Souza, A. M., Lima, E. G., Vallis, M. B., Rocha, M. M., Wittwer, A. R., and Oliveira, M. G. K. (2019). Downburst related damages in Brazilian buildings: are they avoidable? J. Wind Eng. Indus. Aerodyn. 185, 33-40. doi: 10.1016/j.jweia.2018.11.022

Lundgren, T. S., Yao, J., and Mansour, N. N. (1992). Microburst modelling and scaling. J. Fluid Mech. 239, 461-488. doi: 10.1017/S002211209200449X

Mara, T. G., Hong, H. P., Lee, C. S., and Ho, T. C. E. (2016). Capacity of a transmission tower under downburst wind loading. Wind Struct. 22, 65-87. doi: 10.12989/was.2016.22.1.065

Mason, M. S. (2015). “A probabilistic method for estimating regional windstorm occurrence frequency," in 14th International Conference on Wind Engineering (Porto Alegre).

Mason, M. S., Fletcher, D. F., and Wood, G. S. (2010). Numerical simulation of idealised three-dimensional downburst wind fields. Eng. Struct. 32, 3558-3570. doi: 10.1016/j.engstruct.2010.07.024 
Mason, M. S., Letchford, C. W., and James, D. L. (2005). Pulsed jet simulation of a stationary thunderstorm downburst. Part A: physical structure and flow field characterization. J. Wind Eng. Indus. Aerodyn. 93, 557-580. doi: 10.1016/j.jweia.2005.05.006

Mason, M. S., and Wood, G. S. (2005). "Influence of jet inclination on structural loading in an experimentally simulated microburst," in 6th Asia-Pacific Conference on Wind Engineering (Seoul).

Mason, M. S., Wood, G. S., and Fletcher, D. F. (2009). Numerical simulation of downburst winds. J. Wind Eng. Indus. Aerodyn. 97, 523-539. doi: 10.1016/j.jweia.2009.07.010

Mason, M. S., Yanga, T., George, T., Paxton, O., and Wong, E. (2016). “An experimental investigation of the unsteady pressures on square cylinders in a non-stationary wind field," in 8th International Colloquium. on Bluff-Body Aerodynamics and Applications (Boston, MA).

Matsumoto, M., Shimamura, M., Maeda, T., Shirato, H., Yagi, T., Hori, K., et al. (2007). "Drag forces on 2-D cylinders due to sudden increase of wind velocity," in 12th International Conference on Wind Engineering (Cairns, OLD).

McCann, D. W. (1994). WINDEX - A new index for forecasting microburst potential. Weather Forecast. 9, 532- 541. doi: 10.1175/15200434(1994)009<0532:WNIFFM >2.0.CO;2

McConville, A. C., Sterling, M., and Baker, C. J. (2009). The physical simulation of thunderstorm downbursts using an impinging jet. Wind Struct. 12, 133-149. doi: $10.12989 /$ was.2009.12.2.133

McCullough, M., Kwon, D. K., Kareem, A., and Wang, L. (2014). Efficacy of averaging interval for nonstationary winds. J. Eng. Mech. ASCE 140, 1-19. doi: 10.1061/(ASCE)EM.1943-7889.0000641

Middleton, G. V. (1966). Experiments on density and turbidity currents: I. motion of the head. Can. J. Earth Sci. 3, 523-546. doi: 10.1139/ e66-038

Miguel, L. F. F., Riera, J. D., and Miguel, L. F. F. (2018). Assessment of downburst wind loading on tall structures. J. Wind Eng. Indus. Aerodyn. 174, 252-259. doi: 10.1016/j.jweia.2018.01.015

Miller, M. J., and Pearce, R. (1974). A three-dimensional primitive equation model of cumulonimbus convection. Q. J. R. Meteorol. Soc. 100, 133-154. doi: 10.1002/qj.49710042402

Mitchell, K. E., and Hovermale, J. B. (1977). A numerical investigation of the severe thunderstorm gust front. Mon. Weather Rev. 105, 657-675. doi: 10.1175/15200493(1977) 105<0657:ANIOTS>2.0.CO;2

Mohr, S., Kunz, M., Richter, A., and Ruck, B. (2017). Statistical characteristics of convective wind gusts in Germany. Nat. Hazard Earth Syst. 17, 957-969. doi: 10.5194/nhess-17-957-2017

Möller, M. (1884). Untersuchung über die Lufttemperatur und Luftbewegung in einer Böe. Meteorol. Z. 1, 230-243.

Moncrieff, M. W., and Miller, M. J. (1976). The dynamics and simulation of tropical cumulonimbus and squall lines. Q. J. R. Meteorol. Soc. 120, 373-394. doi: 10.1002/qj.49710243208

Nicholls, M., Pielke, R., and Meroney, R. (1993). Large eddy simulation of microburst winds flowing around a building. J. Wind Eng. Indus. Aerodyn. 46-47, 229-237. doi: 10.1016/B978-0-444-81688-7. 50026-7

Nissen, K. M., Leckebusch, G. C., Pinto, J. G., and Ulbrich, U. (2014). Mediterranean cyclones and windstorms in a changing climate. Reg. Environ. Change 14, 1873-1890. doi: 10.1007/s10113-012-0400-8

Ogura, Y. (1963). The evolution of a moist convective element in a shallow, conditionally unstable atmosphere: a numerical calculation. J. Atmos. Sci. 20, 407-424. doi: 10.1175/1520-0469(1963)020<0407:TEOAMC >2.0.CO;2

Ogura, Y., and Phillips, N. A. (1962). Scale analysis of deep and shallow convection in the atmosphere. J. Atmos. Sci. 19, 173-179. doi: 10.1175/15200469(1962)019<0173:SAODAS >2.0.CO;2

Okajima, A., Matsumoto, T., and Kimura, S. (1997). Force measurements and flow visualization of bluff bodies in oscillatory flow. J. Wind Eng. Indus. Aerodyn. 69-71, 213-228. doi: 10.1016/S0167-6105(97)00156-6

Oliver, S. E., Moriarty, W. W., and Holmes, J. D. (2000). A risk model for design of transmission line systems against thunderstorm down burst winds. Eng. Struct. 22, 1173-1179. doi: 10.1016/S0141-0296(99)00057-7

Oreskovic, C., Orf, L. G., and Savory, E. (2018). A parametric study of downbursts using a full-scale cooling source model. J. Wind Eng. Indus. Aerodyn. 180, 168-181. doi: 10.1016/j.jweia.2018.07.020
Oreskovich, C., Savory, E., Porto, J., and Orf, L. G. (2018). Evolution and scaling of a simulated downburst-producing thunderstorm outflow. Wind Struct. 26, 147-161. doi: 10.12989/was.2018.26.3.147

Orf, L. G., and Anderson, J. R. (1999). A numerical study of travelling microbursts. J. Atmos. Sci. 127, 1244-1258. doi: 10.1175/15200493(1999) $127<1244:$ ANSOTM>2.0.CO;2

Orf, L. G., Anderson, J. R., and Straka, J. M. (1997). A three dimensional numerical analysis of colliding microburst outflow dynamics. J. Atmos. Sci. 53, 2490-2511. doi: 10.1175/1520-0469(1996)053<2490:ATDNAO>2.0.CO;2

Orf, L. G., Kantor, E., and Savory, E. (2012). Simulation of a downburst-producing thunderstorm using a very high-resolution three-dimensional cloud model. J. Wind Eng. Indus. Aerodyn. 104-106, 547-557. doi: 10.1016/j.jweia.2012.02.020

Orville, H. D. (1965). A numerical study of the initiation of cumulus clouds over mountainous terrain. J. Atmos. Sci. 24, 1596-1618. doi: 10.1175/15200469(1965)022<0684:ANSOTI >2.0.CO;2

Orwig, K. D., and Schroeder, J. L. (2007). Near-surface wind characteristics of extreme thunderstorm outflows. J. Wind Eng. Indus. Aerodyn. 95, 565-584. doi: 10.1016/j.jweia.2006.12.002

Oseguera, R. M., and Bowles, R. L. (1988). A Simple Analytic 3-Dimensional Downburst Model Based on Boundary Layer Stagnation Flow. NASA Technical Memorandum 100632.

Pagon, W. W. (1934-1935). Aerodynamics and the civil engineers. Eng. News Rec. 1934-1935, 348-353, 41-43, 456-458, 814-819, 582-586, 665-668, 742-745, 601-607.

Peltier, J. C. (1841). Météorologie: Observations et Recherches Expérimentales sur les Causes qui Concourent à la Formation des Trombes. Bruxelles: Société belge de Librairie.

Peng, L., Huang, G., Chen, X., and Yang, Q. (2018). Evolutionary spectrabased time-varying coherence function and application in structural response analysis to downburst winds. J. Struct. Eng. ASCE 144:04018078. doi: 10.1061/(ASCE)ST.1943-541X.0002066

Piccardo, G., and Solari, G. (1998). Generalized equivalent spectrum technique. Wind Struct. 1, 161-174. doi: 10.12989/was.1998.1.2.161

Pistotnik, G., Holzer, A. M., Kaltenböck, R., and Tschannett, S. (2011). An F3 downburst in Austria - a case study with special focus on the importance of realtime site surveys. Atmos. Res. 100, 565-579. doi: 10.1016/j.atmosres.2010.10.011

Ponte, J Jr., and Riera, J. D. (2010). Simulation of extreme wind series caused by thunderstorms in temperate latitudes. Struct. Saf. 32, 131-137. doi: 10.1016/j.strusafe.2010.02.002

Ponte, J. Jr., and Riera, J. D. (2007). Wind velocity field during thunderstorms. Wind Struct. 10, 287-300. doi: 10.12989/was.2007.10.3.287

Poreh, M., Tsuel, Y. G., and Cermak, J. E. (1967). Investigation of a turbulent radial wall jet. J. Appl. Mech. Trans. ASME 34, 457-463. doi: 10.1115/1.3607705

Prein, A. F., Langhans, W., Fosser, G., Ferrone, A., Ban, N., Goergen, K., et al. (2015). A review on regional convection permitting climate modeling: demonstrations, prospects, and challenges. Rev. Geophys. 53, 323-361. doi: 10.1002/2014RG000475

Proctor, F. H. (1987a). The Terminal Area Simulation System. I: Theoretical Formulation. NASA Contractor Report 4046.

Proctor, F. H. (1987b). The Terminal Area Simulation System. II: Verification Cases. NASA Contractor Report 4047.

Proctor, F. H. (1988). Numerical simulations of an isolated micro burst. Part I: dynamics and structure. J. Atmos. Sci. 45, 3137-3159. doi: 10.1175/15200469(1988)045<3137:NSOAIM>2.0.CO;2

Proctor, F. H. (1989). Numerical simulations of an isolated microburst. Part II: sensitivity experiments. J. Atmos. Sci. 46, 2143-2165. doi: 10.1175/15200469(1989)046<2143:NSOAIM>2.0.CO;2

Púcik, T., Groenemeijer, P., Rädler, A. T., Tijssen, L., Nikulin, G., Prein, A. F., et al. (2017). Future changes in European severe convection environments in a regional climate model ensemble. J. Clim. 30, 6771-6794. doi: 10.1175/JCLI-D-16-0777.1

Repetto, M. P., Burlando, M., Solari, G., De Gaetano, P., and Pizzo, M. (2017). Integrated tools for improving the resilience of seaports under extreme wind events. Sustain. Cities Soc. 32, 277-294. doi: 10.1016/j.scs.2017.03.022

Repetto, M. P., Burlando, M., Solari, G., De Gaetano, P., Pizzo, M., and Tizzi, M. (2018). A web-based GIS platform for the safe management and risk assessment of complex structural and infra- structural systems exposed to wind. Adv. Eng. Softw. 117, 29-45. doi: 10.1016/j.advengsoft.2017.03.002 
Richter, A., Ruck, B., Mohr, S., and Kunz, M. (2018). Interaction of severe convective gusts with a street canyon. Urban Clim. 23, 71-90. doi: 10.1016/j.uclim.2016.11.003

Riera, J. D., and Nanni, L. F. (1989). Pilot study of extreme wind velocities in a mixed climate considering wind orientation. J. Wind Eng. Indus. Aerodyn. 32, 11-20. doi: 10.1016/0167-6105(89)90012-3

Riera, J. D., Viollaz, A. J., and Reimundin, J. C. (1977). Some recent results on probabilistic models of extreme wind speeds. J. Indus. Aerodyn. 2, 271-287. doi: 10.1016/0167-6105(77)90027-7

Romanic, D., LoTufo, J., and Hangan, H. (2019). Transient behavior in impinging jets in crossflow with application to downburst flows. J. Wind Eng. Indus. Aerodyn. 184, 209-227. doi: 10.1016/j.jweia.2018.11.020

Rowcroft, J. (2011). "Vertical wind shear profiles in downburst events and the insufficiency of wind turbine design codes," in 13th International Conference on Wind Engineering (Amsterdam).

Sarpkaia, T. (1966). Separated flow about lifting bodies and impulsive flow about cylinders. AIAA J. 4, 414-420. doi: 10.2514/3.3453

Sarpkaya, T. (1963). Lift, drag, and mass coefficients for a circular cylinder immersed in time dependent flow. J. Appl. Mech. 30, 13-15. doi: $10.1115 / 1.3630062$

Sarpkaya, T., and Ihrig, C. (1986). Impulsively started steady flow about rectangular prisms: experiments and discrete vortex analysis. J. Fluids Eng. 108, 47-54. doi: 10.1115/1.3242542

Savory, E., Parke, G. A. R., Zeinoddini, M., Toy, N., and Disney, P. (2001). Modelling of tornado and microburst-induced wind loading and failure of a lattice transmission tower. Eng. Struct. 23, 365-375. doi: 10.1016/S0141-0296(00)00045-6

Schlesinger, R. E. (1975). A three-dimensional numerical model of an isolated deep convective cloud: preliminary results. J. Atmos. Sci. 32, 934-957. doi: 10.1175/ 1520-0469(1975)032<0934:ATDNMO>2.0.CO;2

Schlesinger, R. E. (1978). A three-dimensional numerical model of an isolated thunderstorm. Part I: comparative experiments for variable ambient wind shear. J. Atmos. Sci. 35, 690-713. doi: 10.1175/15200469(1978)035<0690:ATDNMO>2.0.CO;2

Schultz, T. A. (1990). Multiple vortex ring model of the DFW microburst. J. Aircraft 27, 163-168. doi: 10.2514/3.45913

Selvam, R. P., and Holmes, J. D. (1992). Numerical simulation of thunderstorm downdrafts. J. Wind Eng. Indus. Aerodyn. 41-44, 2817-2825. doi: 10.1016/0167-6105(92)90076-M

Sengupta, A., Haan, F., Sarkar, P. P., and Balaramudu, V. (2008). Transient loads on buildings in microburst and tornado winds. J. Wind Eng. Indus. Aerodyn. 96, 2173-2187. doi: 10.1016/j.jweia.2008.02.050

Sengupta, A., and Sarkar, P. P. (2008). Experimental measurement and numerical simulation of an impinging jet with application to thunderstorm microburst winds. J. Wind Eng. Indus. Aerodyn. 96, 345-365. doi: 10.1016/j.jweia.2007.09.001

Shehata, A. Y., El Damatty, A., and Savory, E. (2005). Finite element modelling of transmission line under downburst wind loading. Finite Elem. Anal. Des. 42, 71-89. doi: 10.1016/j.finel.2005.05.005

Shirato, H., Maeta, K., Kato, Y., and Takasugi, Y. (2009). "Transient drag force on 2-D bluff bodies under gusty wind conditions," in 7th Asia-Pacific Conference on Wind Engineering (Taipei).

Showalter, A. K. (1953). A stability index for thunderstorm forecasting. Bull. Am. Meteorol. Soc. 34, 250-252. doi: 10.1175/1520-0477-34.6.250

Simpson, G. C., and Scrase, F. J. (1937). The distribution of electricity in thunderclouds. Proc. R. Soc. Lond. A 161, 309-352. doi: 10.1098/rspa.1937.0148

Simpson, J. E. (1969). A comparison between laboratory and atmospheric density currents. Q. J. R. Meteorol. Soc. 95, 758-765. doi: 10.1002/qj.49709540609

Simpson, J. E. (1972). Effects of the lower boundary on the head of a gravity current. J. Fluid Mech. 53, 759-768. doi: 10.1017/S0022112072000461

Smith, R. L., and Holmes, D. W. (1961). Use of Doppler radar in meteorological observations. Mon. Weather Rev. 89, 1-7. doi: 10.1175/ 1520-0493(1961)089<0001:UODRIM>2.0.CO;2

Solari, G. (1989). Wind response spectrum. J. Eng. Mech. ASCE 115, 2057-2073. doi: 10.1061/(ASCE)0733-9399(1989)115:9(2057)

Solari, G. (2007). The International Association for Wind Engineering (IAWE): progress and prospect. J. Wind Eng. Indus. Aerodyn. 95, 813-842. doi: 10.1016/j.jweia.2007.01.010
Solari, G. (2014). Emerging issues and new frameworks for wind loading on structures in mixed climates. Wind Struct. 19, 295-320. doi: 10.12989/was.2014.19.3.295

Solari, G. (2016). Thunderstorm response spectrum technique: theory and applications. Eng. Struct. 108, 28-46. doi: 10.1016/j.engstruct.2015.11.012

Solari, G. (2019a). "Mixed climatology, non-synoptic phenomena and downburst wind loading of structures," in 15th International Conference of the Italian Association for Wind Engineering (Naples: Springer Science and Business Media LLC). doi: 10.1007/978-3-030-12815-9_2

Solari, G. (2019b). Wind Science and Engineering: Origins, Developments, Fundamentals and Advancements. Springer Science and Business Media LLC. doi: 10.1007/978-3-030-18815-3

Solari, G., Burlando, M., De Gaetano, P., and Repetto, M. P. (2015a). Characteristics of thunderstorms relevant to the wind loading of structures. Wind Struct. 20, 763-791. doi: 10.12989/was.2015.20.6.763

Solari, G., and De Gaetano, P. (2018). Dynamic response of structures to thunderstorm outflows: response spectrum technique vs time-domain analysis. Eng. Struct. 176, 188-207. doi: 10.1016/j.engstruct.2018.08.062

Solari, G., De Gaetano, P., and Repetto, M. P. (2015b). Thunderstorm response spectrum: fundamentals and case study. J. Wind Eng. Indus. Aerodyn. 143, 62-77. doi: 10.1016/j.jweia.2015.04.009

Solari, G., Rainisio, D., and De Gaetano, P. (2017). Hybrid simulation of thunderstorm outflows and wind-excited response of structures. Meccanica 52, 3197-3220. doi: 10.1007/s11012-017-0718-x

Solari, G., Repetto, M. P., Burlando, M., De Gaetano, P., Pizzo, M., Tizzi, M., et al. (2012). The wind forecast for safety and management of port areas. J. Wind Eng. Indus. Aerodyn. 104-106, 266-277. doi: 10.1016/j.jweia.2012.03.029

Srivastava, R. C. (1985). A simple model of evaporatively driven downdraft: application to microburst downdraft. J. Atmos. Sci. 42, 1004-1023. doi: 10.1175/ 1520-0469(1985)042<1004:ASMOED>2.0.CO;2

Steiner, J. T. (1973). A three-dimensional model of cumulus cloud development. J. Atmos. Sci. 30, 414-435. doi: 10.1175/1520-0469(1973)030<0414:ATDMOC >2. $0 . \mathrm{CO} ; 2$

Stengel, D., and Klaus, T. (2017). Measurements of downburst wind loading acting on an overhead transmission line in Northern Germany. Procedia Eng. 199, 3152-3157. doi: 10.1016/j.proeng.2017.09.578

Straka, J. M., and Anderson, J. R. (1993). Numerical simulations of microburst producing storms: some results from storms observed during COHMEX. J. Atmos. Sci. 50, 1329-1348. doi: 10.1175/15200469(1993)050<1329:NSOMPS>2.0.CO;2

Su, Y., Huang, G., and Xu, Y. L. (2015). Derivation of time-varying mean for non-stationary downburst winds. J. Wind Eng. Indus. Aerodyn. 141, 39-48. doi: 10.1016/j.jweia.2015.02.008

Suckstorff, G. A. (1938). Kaltlufterzeugung durch Niederschlag. Z. Meteorol. $55,287-292$

Tajbakhsh, S., Ghafarian, P., and Sahraian, F. (2012). Instability indices and forecasting thunderstorms: the case of 30 April 2009. Nat. Hazard Earth Syst. 12, 403-413. doi: 10.5194/nhess-12-403-2012

Takeuchi, T., Maeda, J., Kawakami, R., and Takeuchi, N. (2016). "Effects of wind direction and roof shape on unsteady wind pressure on a low rise building under a short-rise-time gust," in 8th International Colloquium on Bluff-Body Aerodynamics and Applications (Boston, MA).

Takeuchi, T., Maeda, J., and Kawashita, H. (2008). "The overshoot of aerodynamic forces on a railcar-like body under step-function-like gusty winds," in 6th International Colloquium on Bluff-Body Aerodynamics and Applications (Milan)

Takeuchi, T., Maeda, J., Otsubo, K., and Shuto, Y. (2012). "Unsteady wind force on an elliptic cylinder subjected to a short-rise-time gust from steady flow" in 7th International Colloquium on Bluff-Body Aerodynamics and Applications (Shanghai).

Tamai, H., Okuda, Y., and Katsura, J. (2001). On relation between Reynolds number and Karman vortex formation on a bluff body in natural wind. J. Wind Eng. Indus. Aerodyn. 89, 1619-1633. doi: 10.1016/S0167-6105(01)00133-7

Thom, H. C. S. (1968a). "Toward a universal climatological extreme wind distribution," in 2nd International Conference on Wind Effects on Buildings and Structures (Ottawa, ON).

Thom, H. C. S. (1968b). New distributions of extreme wind speeds in the United States. J. Struct. Div. ASCE 94, 1787-1801. 
Trapp, R., Diffenbaugh, N. S., Brooks, H. E., Baldwin, M. E., Robinson, E. D., and Pal, J. S. (2007). Changes in severe thunderstorm environment frequency during the 21 st century caused by anthropogenically enhanced global radiative forcing. Proc. Natl. Acad. Sci. U.S.A. 104, 19719-19723. doi: 10.1073/pnas.0705494104

Trapp, R. J., Hoogewind, K. A., and Gluhovsky, A. (2009). Transient response of severe thunderstorm forcing to elevated greenhouse gas concentrations. Geophys. Res. Lett. 36:L01703. doi: 10.1029/2008GL0 36203

Twisdale, L. A., and Vickery, P. J. (1992). Research on thunderstorm wind design parameters. J. Wind Eng. Indus. Aerodyn. 41, 545-556. doi: 10.1016/0167-6105(92)90461-I

Vallis, M. B., Loredo-Souza, A. M., Ferreira, V., and De Lima Nascimento, E. (2019). Classification and identification of synoptic and non-synoptic extreme wind events from surface observations in South America. J. Wind Eng. Indus. Aerodyn. 193:103963. doi: 10.1016/j.jweia.2019. 103963

Van der Hoven, I. (1957). Power spectrum of horizontal wind speed in the frequency range from 0.0007 to 900 cycles per hour. J. Meteorol. 14, 160-164. doi: 10.1175/1520-0469(1957)014<0160:PSOHWS >2.0.CO;2

Vermeire, B. C., Orf, L. G., and Savory, E. (2011a). A parametric study of downburst line near-surface outflows. J. Wind Eng. Indus. Aerodyn. 99, 226-238. doi: 10.1016/j.jweia.2011.01.019

Vermeire, B. C., Orf, L. G., and Savory, E. (2011b). Improved modeling of downburst outflows for wind engineering applications using a cooling source approach. J. Wind Eng. Indus. Aerodyn. 99, 801-814. doi: 10.1016/j.jweia.2011.03.003

Vickery, P. J., Masters, F. J., Powell, M. D., and Wadhera, D. (2009). Hurricane hazard modeling: the past, present and future. J. Wind Eng. Indus. Aerodyn. 97, 392-405. doi: 10.1016/j.jweia.2009.05.005

Vicroy, D. D. (1991). A Simple, Analytical, Axisimmetric Microbust Model for Downdraft Estimation. NASA Technical Memorandum 104053.

Vicroy, D. D. (1992). Assessment of micro burst models for downdraft estimation. J. Aircraft 29, 1043-1048. doi: 10.2514/3.46282

Wakimoto, R. M. (1982). The life cycle of thunderstorm gust fronts as viewed with Doppler radar and rawinsonde data. Mon. Weather Rev. 110, 1060-1082. doi: 10.1175/1520-0493(1982)110<1060:TLCOTG >2.0.CO;2

Wang, D., Chen, X., and Xu, K. (2017). Analysis of buffeting response of hinged overhead transmission conductor to nonstationary winds. Eng. Struct. 147, 567-582. doi: 10.1016/j.engstruct.2017.06.009

Wang, L., McCullough, M., and Kareem, A. (2013). A data-driven approach for simulation of full-scale downburst wind speeds. J. Wind Eng. Indus. Aerodyn. 123, 171-190. doi: 10.1016/j.jweia.2013.08.010

Wang, L., McCullough, M., and Kareem, A. (2014). Modelling and simulation of nonstationary processes utilizing wavelet and Hilbert transforms. J. Eng. Mech. ASCE 140, 345-360. doi: 10.1061/(ASCE)EM.1943-7889.0000666

Wilson, J. W., Roberts, R. D., Kessinger, C., and McCarthy, J. (1984). Microburst wind structure and evaluation of Doppler radar for airport wind shear detection. J. Clim. Appl. Meteorol. 23, 898-915. doi: 10.1175/15200450(1984)023<0898:MWSAEO>2.0.CO;2

Wilson, J. W., and Wakimoto, R. M. (2001). The discovery of the downburst: T.T. Fujita's contribution. Bull. Am. Meteorol. Soc. 82, 49-62.2.3. doi: 10.1175/15200477(2001)082<0049:TDOTDT>2.3.CO;2

Wittingham, H. E. (1964). Extreme Wind Gusts in Australia. Bulletin 46, Commonwealth Australian Bureau of Meteorology.

Wood, G. S., and Kwok, K. C. S. (1998). “An empirically derived estimate for the mean velocity profile of a thunderstorm downburst," in 7th Australian Wind Engineering Society Workshop (Auckland).

Wood, G. S., Kwok, K. C. S., Motteram, N. A., and Fletcher, D. F. (2001). Physical and numerical modelling of thunderstorm downburst. J. Wind Eng. Indus. Aerodyn. 89, 535-552. doi: 10.1016/S0167-6105(00)00090-8
$\mathrm{Xu}$, Y. L., and Chen, J. (2004). Characterizing nonstationary wind speed using empirical mode decomposition. J. Struct. Eng. ASCE 130, 912-920. doi: 10.1061/(ASCE)0733-9445(2004)130:6(912)

Xu, Y. L., Hu, L., and Kareem, A. (2014). Conditional simulation of nonstationary fluctuating wind speeds for long-span bridges. J. Eng. Mech. ASCE 140, 61-73. doi: 10.1061/(ASCE)EM.1943-7889.0000589

$\mathrm{Xu}, \mathrm{Z}$., and Hangan, H. (2008). Scale, boundary and inlet condition effects on impinging jets. J. Wind Eng. Indus. Aerodyn. 96, 2383-2402. doi: 10.1016/j.jweia.2008.04.002

$\mathrm{Xu}, \mathrm{Z}$., Hangan, H., and Yu, P. (2008). Analytical solutions for a family of Gaussian impinging jets. J. Appl. Mech. 75:021019-1-12. doi: 10.1115/1.2775502

Yang, S. C., and Hong, H. P. (2016). Nonlinear inelastic responses of transmission tower-line system under downburst wind. Eng. Struct. 123, 490-500. doi: 10.1016/j.engstruct.2016.05.047

Yang, T., and Mason, M. (2019). Aerodynamic characteristics of rectangular cylinders in steady and accelerating wind flow. J. Fluids Struct. 90, 246-262. doi: 10.1016/j.jfluidstructs.2019.07.004

Yao, J., and Lundgren, T. S. (1996). Experimental investigation of microbursts. Exp. Fluids. 21, 17-25. doi: 10.1007/BF00204631

Zhang, S., Solari, G., Burlando, M., and Yang, Q. (2019a). Directional decomposition and analysis of thunderstorm outflows. J. Wind Eng. Indus. Aerodyn. 189, 71-90. doi: 10.1016/j.jweia.2019.03.014

Zhang, S., Solari, G., De Gaetano, P., Burlando, M., and Repetto, M. P. (2018a). A refined analysis of thunderstorm outflow characteristics relevant to the wind loading of structures. Probabil Eng. Mech. 54, 9-24. doi: 10.1016/j.probengmech.2017.06.003

Zhang, S., Solari, G., Yang, Q., and Repetto, M. P. (2018b). Extreme wind speed distribution in a mixed wind climate. J. Wind Eng. Indus. Aerodyn. 176, 239-253. doi: 10.1016/j.jweia.2018.03.019

Zhang, S., Yang, Q., Solari, G., Li, B., and Huang, G. (2019b). Characteristics of thunderstorm outflows in Beijing urban area. J. Wind Eng. Indus. Aerodyn. 195:104011. doi: 10.1016/j.jweia.2019.104011

Zhang, Y., Hu, H., and Sarkar, P. P. (2013a). Modeling of microburst outflows using impinging jet and cooling source approaches and their comparison. Eng. Struct. 56, 779-793. doi: 10.1016/j.engstruct.2013.06.003

Zhang, Y., Hu, H., and Sarkar, P. P. (2014a). Comparison of microburst-wind loads on low-rise structures of various geometric shapes. J. Wind Eng. Indus. Aerodyn. 133, 181-190. doi: 10.1016/j.jweia.2014.06.012

Zhang, Y., Sarkar, P., and Hu, H. (2013b). An experimental study of flow fields and wind loads on gable-roof building models in microburst-like wind. Exp. Fluids 54, 1511. doi: 10.1007/s00348-013-1511-9

Zhang, Y., Sarkar, P., and $\mathrm{Hu}, \mathrm{H}$. (2014b). An experimental study on wind loads acting on a high-rise building model induced by microburstlike winds. J. Fluid Struct. 50, 547-564. doi: 10.1016/j.jfluidstructs.2014. 07.010

Zhang, Y., Sarkar, P. P., and Hu, H. (2015). "Factors influencing internal pressure in a low rise building subject to a microburst," in 14th International Conference on Wind Engineering (Porto Alegre).

Zhu, S., and Etkin, B. (1985). Model of the wind field in a downburst. J. Aircraft 22, 595-601. doi: 10.2514/3.45171

Conflict of Interest: The author declares that the research was conducted in the absence of any commercial or financial relationships that could be construed as a potential conflict of interest.

Copyright (C) 2020 Solari. This is an open-access article distributed under the terms of the Creative Commons Attribution License (CC BY). The use, distribution or reproduction in other forums is permitted, provided the original author $(s)$ and the copyright owner(s) are credited and that the original publication in this journal is cited, in accordance with accepted academic practice. No use, distribution or reproduction is permitted which does not comply with these terms. 